\title{
Application of Low-Salinity Waterflooding in Carbonate Cores: A Geochemical Modeling Study
}

\author{
Daniel Isong Otu Egbe, ${ }^{1}$ Ashkan Jahanbani Ghahfarokhi, ${ }^{2,4}$ Menad Nait Amar, ${ }^{3}$ and \\ Ole Torsater ${ }^{2}$
}

Received 6 February 2020; accepted 5 June 2020

Published online: 20 June 2020

Waterflooding is the most widely applied improved oil recovery technique. Recently, there has been growing interest in the chemistry and ionic composition of the injected water. Lowsalinity waterflooding (LSWF) is a relatively recent enhanced oil recovery technique that has the ability to alter the crude oil/brine/rock interactions and improve oil recovery in both clastics and carbonates. In this paper, the increase in the recovery factor during LSWF was modeled based on the exchange of divalent cations $\left(\mathrm{Ca}^{2+}\right.$ and $\left.\mathrm{Mg}^{2+}\right)$ between the aqueous phase and the carbonate rock surface. Numerical simulations were performed using laboratory coreflood data, and oil recovery and pressure drop from experimental works were successfully history matched. The ion exchange equivalent fractions, effluent ions concentrations, changes in mineral moles, and $\mathrm{pH}$ have also been examined. Besides, an investigation of multi-component ionic exchange as a mechanism responsible for wettability alteration during LSWF in heterogeneous low-permeability carbonate cores is presented. The results show that wettability alteration is responsible for the increase in oil recovery during LSWF, as reflected by the shift in the crossover points of the relative permeability curves. A sensitivity study done on many key parameters (e.g., timing of LSWF injection, injection rate and temperature) and the mechanistic modeling method revealed that they all have huge effects on the process.

KEY WORDS: Low-salinity waterflooding, Wettability alteration, Multi-component ion exchange, Low-salinity effects, Geochemical modeling.

\section{INTRODUCTION}

Carbonate reservoirs are estimated to hold about $60 \%$ and $40 \%$ of the world's oil and gas reserves, respectively. Despite the significant amount of oil and gas in carbonate reservoirs, they have

\footnotetext{
${ }^{1}$ Vår Energi AS, Stavanger, Norway.

${ }^{2}$ Department of Geoscience and Petroleum, Norwegian University of Science and Technology, Trondheim, Norway.

${ }^{3}$ Département Etudes Thermodynamiques, Division Laboratoires, Sonatrach, Boumerdes, Algeria.

${ }^{4}$ To whom correspondence should be addressed; e-mail: ashkan.jahanbani@ntnu.no
}

been very challenging to understand and develop due to their heterogeneous nature, which results from the combination of depositional geometry and diagenesis. This, coupled with the fact that about $90 \%$ of carbonate rocks are either neutral or oil-wet, has resulted in much lower primary recoveries (average of $30 \%$ ) compared to sandstones (Sun and Sloan 2003; Adegbite et al. 2018).

Waterflooding has been and is currently the most widely used method to increase production from oil reservoirs worldwide because it is economical, easily accessible and reliable (Craig 1971; Dang et al. 2015). It is classified as a secondary recovery mechanism that helps to increase produc- 
tion and maintain reservoir pressure. Initially, less attention was dedicated to the effects of the chemistry and ionic composition of injected brine. However, it has recently been reported that modifying the salinity of the injected brine by dilution can lead to incremental oil recovery. This is known as lowsalinity waterflooding (LSWF) (Al-Shalabi et al. 2015). Other names such as smart waterflooding, advanced ion management, engineered water injection, designer waterflood and LoSal are used in the literature. However, it should be noted that engineered (smart) waterflooding is slightly different from LSWF because it involves modifying the ionic composition of the injected brine.

Many laboratory studies (Lager et al. 2006, 2008; Al-Attar et al. 2013; Hamouda and Gupta 2017; Nasralla et al. 2018) have reported an increase in oil recovery in carbonates from LSWF as well as a few field studies (Yousef et al. 2012). Despite the growing interest in the process, there is currently no consensus on the mechanisms responsible for the increase in oil recovery, and it is believed that a combination of mechanisms contributes to the observed low-salinity effects (LSEs). However, wettability alteration is widely accepted to be the primary mechanism.

The LSWF process is less understood in carbonates than in sandstones because of their very heterogeneous nature and lack of clay minerals and because of the high bonding energy that exists between the surface of carbonate rocks and the polar components in crude oil (Lager et al. 2008; RezaeiDoust et al. 2009; Derkani et al. 2018). Chilingar and Yen (1983) asserted that about $80 \%$ of carbonate reservoir rocks are oil-wet, which has an adverse effect on oil recovery by waterflooding. Altering the wettability of a carbonate reservoir rock from more oil-wet to less oil-wet by LSWF could, therefore, help increase oil recovery from the reservoir. The existing wettability alteration mechanisms include multi-component ionic exchange, expansion of the electrical double layer, rock dissolution, fines migration, interfacial tension decrease, $\mathrm{pH}$ increase and formation of microdispersions. A review of the different mechanisms is presented below.

Zhang et al. $(2006,2007)$ proposed a multicomponent ionic exchange mechanism that involves a process between the potential determining ions $\left(\mathrm{Mg}^{2+}, \mathrm{Ca}^{2+}\right.$, and $\left.\mathrm{SO}_{4}{ }^{2-}\right)$ in the injected brine and the carbonate rock surface. $\mathrm{SO}_{4}{ }^{2-}$ ions adsorb onto the positively charged carbonate surface, reducing electrostatic repulsion. $\mathrm{Ca}^{2+}$ ions then adsorb and react with the carboxylic group bonded to the carbonate rock surface. This results in the release of some carboxylic materials from the rock surface, a change in wettability and an increase in oil recovery. The study also investigated the effect of temperature on the process and found that the adsorption of $\mathrm{SO}_{4}{ }^{2-}$ and co-adsorption of $\mathrm{Ca}^{2+}$ increased with temperature. It was also found that the degree of substitution of $\mathrm{Ca}^{2+}$ by $\mathrm{Mg}^{2+}$ on the carbonate surface increased with temperature.

Hiorth et al. (2008) proposed dissolution of calcite as the main wettability alteration mechanism. A geochemical model was developed and tested using experimental data. They believed that if a change in surface potential was responsible for lowsalinity effects, it should be observed at both high and low temperatures. This was, however, not the case based on the results from their model. In addition, they suggested that the adsorption of oil components onto the carbonate rock surface is a strong and irreversible process, and, therefore, the equilibrium between the rock surface and oil should not be affected by a change in water chemistry. Based on the observations, they proposed rock dissolution as a mechanism for wettability alteration in carbonates.

An innovative approach to investigate dissolution and dissolution-induced fines migration using a heterogeneous limestone core was developed by Altahir et al. (2017). Scanning electron microscope images were taken before and after coreflood experiments to investigate the potential of dissolution to alter the rock geometry and for comparison purposes. Ionic chromatography was also used to quantify the concentrations of anions and cations produced in the effluent. Fines migration was observed in all the images, and dissolution was proposed as the mechanism for fines migration. In addition, no pressure drop was observed and this was attributed to the coexistence of dissolution and fines migration. Finally, an increase in $\mathrm{pH}$ was observed, which was considered as further confirmation of the dissolution of calcite.

The role of crude oil/brine/rock interactions and the formation of micelles were investigated by Sohrabi et al. (2017). Significant additional oil recovery was observed in clay-free porous medium, which they believed was due to the formation of micelles. It is believed that micro-dispersions are formed in the oil phase when low-salinity water comes in contact with crude oil, and the micro-dis- 
persions deplete the surface-active components at the oil/brine interface. This changes the balance of forces at the rock/brine and oil/brine interfaces and results in wettability alteration.

A literature review of the modeling studies of LSWF is given in the following section. Most of the modeling studies in carbonates have either used a homogeneous model or a heterogeneous model with relatively high permeability. This paper presents the results of LSWF modeling performed on a heterogeneous carbonate core of very low permeability $(<2 \mathrm{md})$ and demonstrates that it is possible to model the effects of LSWF even in very low-permeability carbonates. A systematic investigation of the effects of different input parameters on the process is presented. The sensitivity study showed that the number of grid blocks and their dimensions are crucial for capturing the geochemical interactions during the process. The modeling shows that cation exchange can sometimes be used to model LSWF in carbonates instead of the conventional anion exchange. This insight can be extended to the field scale, for history matching and prediction of oil recovery from LSWF.

\section{INSIGHT TO CONTRIBUTING PARTS IN MODELING OF LSWF}

\section{Numerical Modeling}

Reservoir modeling is a valuable tool for the verification and validation of experimental results and for predictions at conditions beyond the scope of experimental work (Derkani et al. 2018). However, the number of LSWF modeling studies in carbonates is fewer than in sandstones, and most of the studies focused on understanding the mechanisms responsible for incremental oil recovery in carbonates through laboratory studies. In addition, modeling the geochemical reactions between the carbonate rock surface and the aqueous phases is not an easy task due to the complex nature of the crude oil/brine/rock interactions and heterogeneity in carbonates (Adegbite et al. 2018).

Jerauld et al. $(2006,2008)$ presented one of the first models on LSWF, which considered salt as an additional component lumped in the aqueous phase. Relative permeability, capillary pressure and aqueous phase density and viscosity were all modeled as functions of salinity. Residual oil saturation $\left(S_{\text {orw }}\right)$ was assumed to be linearly dependent on salinity.
The model equations for water and oil relative permeabilities $\left(k_{\mathrm{rw}}\right.$ and $\left.k_{\text {row }}\right)$ and capillary pressure $\left(P_{\text {cow }}\right)$ are as follows:

$$
\begin{gathered}
k_{\mathrm{rw}}=\theta k_{\mathrm{rw}}^{\mathrm{HS}}\left(S^{*}\right)+(1-\theta) k_{\mathrm{rw}}^{\mathrm{LS}}\left(S^{*}\right) \\
k_{\mathrm{row}}=\theta k_{\mathrm{row}}^{\mathrm{HS}}\left(S^{*}\right)+(1-\theta) k_{\mathrm{row}}^{\mathrm{LS}}\left(S^{*}\right) \\
P_{\mathrm{cow}}=\theta P_{\mathrm{cow}}^{\mathrm{HS}}\left(S^{*}\right)+(1-\theta) P_{\mathrm{cow}}^{\mathrm{LS}}\left(S^{*}\right)
\end{gathered}
$$

where

$$
\begin{gathered}
\theta=\left(S_{\text {orw }}-S_{\text {orw }}^{\mathrm{LS}}\right) /\left(S_{\text {orw }}^{\mathrm{HS}}-S_{\text {orw }}^{\mathrm{LS}}\right) \\
S *=\left(S_{o}-S_{\text {orw }}\right) /\left(1-S_{\mathrm{wr}}-S_{\text {orw }}\right)
\end{gathered}
$$

$\theta$ is scaling factor, $S^{*}$ is the normalized oil saturation, $H S$ and LS refer to high and low salinities, respectively, $S$ denotes phase saturation, and subscript $r$ refers to residual saturation.

Although the same scaling factor proposed by Jerauld et al. (2008) is currently used in most LSWF models, the need to use scaling parameters for handling relative permeability and capillary pressure of oil and water separately has been pointed out by Al-Shalabi et al. (2013). They used UTCHEM (an in-house simulator developed at the University of Texas at Austin) to simulate and history match coreflood experiments done on composite carbonate cores. It was observed that LSWF had negligible effect on the endpoint water relative permeability and Corey water exponent. The need for geochemical modeling of LSWF to investigate the change in surface charge and expansion of the electrical double layer was also highlighted.

Dang et al. $(2015,2016)$ developed a comprehensive ion exchange model that captures the geochemical reactions that occur during LSWF. The model was coupled with the compositional simulator $\mathrm{GEM}^{\mathrm{TM}}$ from CMG and was validated with the ion exchange model of PHREEQC and two coreflood experiments, for a North Sea reservoir and a heterogeneous Texas sandstone reservoir core. The geochemistry model was used to evaluate LSWF optimization through well placement, and the authors investigated the potential of a hybrid enhanced oil recovery process that involved combining LSWF and $\mathrm{CO}_{2}$ injection in a miscible water-alternatinggas process.

A geochemical model that uses the equivalent fraction of divalent cations $\left(\mathrm{Ca}^{2+}\right.$ and $\left.\mathrm{Mg}^{2+}\right)$ was proposed by Awolayo and Sarma (2017). The model was used to history match several carbonate core- 
flood experiments. Based on the simulation results, they concluded that the interplay between surface charge alteration and mineral dissolution was the key to improved oil recovery at core scale.

\section{Geochemistry}

During LSWF, the initial thermodynamic equilibrium of a system is disrupted through geochemical reactions that occur at the rock/brine interface (Dang et al. 2015; Adegbite et al. 2018; Jahanbani and Torsæter 2018, 2019). The geochemical reactions can be divided into homogeneous and heterogeneous reactions. Homogeneous reactions occur among the aqueous phase components and are known as intraaqueous reactions whereas the heterogeneous reactions occur between the aqueous components and mineral species, such as mineral dissolution/precipitation and ion exchange reactions (Computer Modelling Group Ltd. 2018). The two types of reactions are typically represented as chemical equilibrium reactions and rate-dependent reactions, respectively, because intra-aqueous reactions are relatively faster than mineral dissolution/precipitation reactions.

\section{Intra-aqueous Reactions}

According to Bethke (1996), equilibrium constants are used in modeling chemical equilibrium reactions. For a chemical reaction to be in thermodynamic equilibrium, the rate of forward and backward reactions must be equal, implying that the activity product of the reaction must be equal to its equilibrium constant. This concept gives rise to the following governing equations for chemical equilibrium reactions:

$$
\begin{gathered}
Q_{\alpha}-K_{\mathrm{eq}, \alpha}=0, \alpha=1, \ldots, R_{\mathrm{aq}} \\
Q_{\alpha}=\prod_{i=1}^{n_{a q}} a_{i}^{v_{i x}}
\end{gathered}
$$

where $K_{\text {eq }, \alpha}$ is the equilibrium constant for aqueous reaction $\alpha, R_{\mathrm{aq}}$ is the number of aqueous phase reactions, $Q_{\alpha}$ is the activity product and $a_{i}$ and $v_{i \alpha}$ are the activity and the stoichiometry coefficients of component $i$, respectively. The aqueous phase consists of both the components that only exist in the aqueous phase $\left(n_{a}\right)$ and the gaseous components that are soluble in the aqueous phase $\left(n_{c}\right)$. The total number of components in the aqueous phase, $n_{\mathrm{aq}}$, is the sum of the two. The aqueous species can also be divided into independent (primary) and dependent (secondary) aqueous species.

Tables of values of equilibrium constants for many reactions as a function of temperature have been presented by some authors (e.g., Kharaka et al. 1989; Delaney and Lundeen 1990). The relationship between the activity of component $i\left(a_{i}\right)$ and its molality $\left(m_{i}\right)$ is given by Eq. 8 . The molality of a component is its moles per kilogram of water and is expressed in molal $(\mathrm{m})$, thus:

$$
a_{i}=\gamma_{i} m_{i}, \quad i=1, \ldots, n_{\mathrm{aq}}
$$

where $\gamma_{i}$ is the activity coefficient. The activity of an ideal solution is equal to its molality as $\gamma_{i}=1$. However, most solutions are non-ideal and a value other than one is required for $\gamma_{i}$. Many models exist for calculating the activity coefficients of electrolytic solutions such as the Debye-Hückel equation, the Davies equation and the B-Dot model (Bethke 1996). An activity coefficient model describes the relation between a component's activity coefficient and the ionic strength of the solution. The Davies and B-Dot models are variants of the Debye-Hückel equation developed by Debye and Hückel in 1923. In $\mathrm{GEM}^{\mathrm{TM}}$, computations of ionic activity coefficients are done using the B-Dot model. This is widely applied in many geochemical models, because it can accurately predict the activity coefficients of components over a wider range of temperatures $\left(0-300{ }^{\circ} \mathrm{C}\right.$ ) and molalities (up to $3 \mathrm{~m}$ ) compared to other models. The equations for the BDot model and ionic strength are, respectively:

$$
\begin{gathered}
\log \gamma_{i}=-\frac{A_{\gamma} z_{i}^{2} \sqrt{I}}{1+\dot{a}_{i} B_{\gamma \sqrt{I}}}+\dot{B} \\
I=\frac{1}{2} \sum_{i=1}^{n_{\mathrm{aq}}} m_{i} z_{i}^{2}
\end{gathered}
$$

where $A, B$ and $\dot{B}$ are temperature-dependent coefficients, $\dot{a}_{i}$ is the ion size parameter (constant), $z_{i}$ is the valence number of component $i$ and $m_{i}$ is its molality.

\section{Mineral Dissolution/Precipitation Reactions}

Reactions involving minerals and aqueous species are slower than aqueous reactions and are 
modeled using kinetic rate laws (Bethke 1996). The expression for the rate law for mineral dissolution and precipitation is:

$$
r_{\beta}=\widehat{A_{\beta}} k_{\beta}\left(1-\frac{Q_{\beta}}{K_{\text {eq }, \beta}}\right), \quad \beta=1, \ldots R_{m n}
$$

where $r$ is the reaction rate, $\widehat{A_{\beta}}$ is the reactive surface area of mineral reaction $\beta, k$ is the rate constant, $K_{\text {eq, } \beta}$ is the equilibrium constant, $Q$ is the activity product for mineral reaction $\beta$, and $R_{m n}$ is the number of mineral reactions. $Q$ is similar to the activity product for aqueous chemical equilibrium reactions, and thus:

$$
Q_{\beta}=\prod_{i=1}^{n_{\mathrm{aq}}} a_{i}^{v_{i \alpha}}
$$

The activities of minerals are equal to unity and are, therefore, eluded in the above equation. The ratio $\left(Q_{\beta} / K_{\mathrm{eq}, \beta}\right)$ in Eq. 11 is called the saturation index. Mineral dissolution occurs if $\log$ $\left(Q_{\beta} / K_{\text {eq }, \beta}\right)<0$, while mineral precipitation occurs if $\log \left(Q_{\beta} / K_{\text {eq }, \beta}\right)>0$. If $\log \left(Q_{\beta} / K_{\text {eq }, \beta}\right)=0$, the mineral is in equilibrium with the aqueous phase and no reaction occurs $(r=0)$. Equation (applies to minerals only. The rate of formation/consumption of different aqueous species is obtained by multiplying by the respective stoichiometry coefficient (Nghiem et al. 2004):

$$
r_{i \beta}=v_{i \beta} \cdot r
$$

Reaction rate constants are normally reported in the literature at a reference temperature, $T_{0}$ (usually $298.15 \mathrm{~K}$ or $25^{\circ} \mathrm{C}$ ). The temperature of petroleum reservoirs is typically higher than $T_{0}$. To calculate the rate constant at a different temperature $T$, Eq. 14 is used:

$$
k_{\beta}=k_{0 \beta} \exp \left[-\frac{E_{a \beta}}{R}\left(\frac{1}{T}-\frac{1}{T_{0}}\right)\right]
$$

where $E_{a \beta}$ and $k_{0 \beta}$ are the activation energy for reaction $\beta(\mathrm{J} / \mathrm{mol})$ and the rate constant for reaction $\beta$ at the reference temperature, respectively, and $R$ is the universal gas constant $(8.314 \mathrm{~J} / \mathrm{mol}-\mathrm{K})$. Both $T$ and $T_{0}$ are in Kelvin $(K)$. The activation energy $\left(E_{a}\right)$ of the chemical reactions that result in wettability modification during LSWF is very important because if the reaction rate is low, it would take a long time for any LSEs to be observed due to slower interactions between the rock and the injected brine. The activation energy is related to how strongly the polar oil components are bonded to the mineral surface, and the reactivity of the ions in the injected water. The bonding energy between polar components in oil and carbonates is generally higher than that between the oil and clays in sandstones (RezaeiDoust et al. 2009).

The equilibrium constants for aqueous and mineral reactions are calculated as a function of reservoir temperature, $T$, using:

$$
\log \left(K_{\mathrm{eq}}\right)=a_{0}+a_{1} T+a_{2} T^{2}+a_{3} T^{3}+a_{4} T^{4}
$$

The default values of $a_{0}, a_{1}, a_{2}, a_{3}, a_{4}$ for different reactions are specified in GEM's internal library and the reservoir temperature, $T$ is $90.6{ }^{\circ} \mathrm{C}$.

As mineral dissolution/precipitation occurs, the surface area available to reactions also changes, and so the reactive surface area is an important parameter when calculating the reaction rate (Nghiem et al. 2004; Computer Modelling Group Ltd. 2018). The reactive surface area $\left(\widehat{A_{\beta}}\right)$ as minerals dissolve/precipitate is calculated as:

$$
\widehat{A_{\beta}}=\widehat{A_{\beta}^{0}} \cdot \frac{N_{\beta}}{N_{\beta}^{0}}
$$

where $N$ is the number of moles of mineral $\beta$ per unit bulk volume. $\widehat{A_{\beta}^{0}}$ and $N_{\beta}^{0}$ are the initial parameters. In addition, both porosity and permeability of a porous medium would alter as a result of mineral dissolution/precipitation. Equations 17 and 18 are used for calculating porosity:

$$
\begin{aligned}
\widehat{\phi^{*}} & =\phi^{*}-\sum_{\beta=1}^{n_{m}}\left(\frac{N_{\beta}}{\rho_{\beta}}-\frac{N_{\beta}^{0}}{\rho_{\beta}}\right) \\
\phi & =\widehat{\phi}^{*}\left[1+c_{\phi}\left(p-p^{*}\right)\right]
\end{aligned}
$$

where $\phi$ is the updated porosity, $\phi^{*}$ is the reference porosity with no mineral dissolution/precipitation, $\widehat{\phi^{*}}$ is the porosity with dissolution/precipitation, $\rho$ is the mineral's molar density, $c$ is the rock compressibility, $p$ and $p^{*}$ are the current and reference pressures, respectively. To calculate the permeability, the Kozeny-Carman equation is used:

$$
\frac{k}{k^{0}}=\left(\frac{\phi}{\phi^{0}}\right)^{3} \cdot\left(\frac{1-\phi^{0}}{1-\phi}\right)^{2}
$$

where $k^{0}$ is the initial permeability and $\phi^{0}$ is the initial porosity. 


\section{Ion Exchange Reactions}

When water is injected (with a different ionic composition compared to the formation water), multiple ion exchange and geochemical reactions occur between the ions in the aqueous phase and the rock surface. The exchange reactions are fast and homogeneous and are, therefore, modeled as chemical equilibrium reactions. The multiple ion exchange and geochemical reactions are key to the increase in oil recovery during LSWF though they differ with the rock type. Sulfate ions are adsorbed from the aqueous phase during LSWF onto carbonates, which reduce the surface charge allowing the adsorption of cations from the aqueous phase.

In this study, multi-component ion exchange and the resulting wettability alteration during LSWF are modeled using the exchange of divalent cations; $\mathrm{Ca}^{2+}$ and $\mathrm{Mg}^{2+}$. The ion exchange reactions are shown in Table 1 . The $X$ in the reactions represents the ion exchanger on the carbonate rock surface. During LSWF, $\mathrm{Ca}^{2+}$ and $\mathrm{Mg}^{2+}$ are taken up by the exchanger, while $\mathrm{Na}^{+}$is released. The reverse process occurs during high-salinity waterflooding. Ion exchange reactions are characterized by equilibrium constants (Computer Modelling Group Ltd. 2018), and thus:

Table 1. List of aqueous, mineral and ion exchange reactions used in simulations

\begin{tabular}{|c|c|}
\hline Aqueous reactions & Equilibrium constants \\
\hline 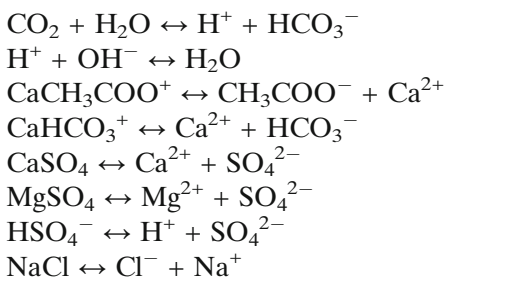 & $\begin{array}{l}K_{1}^{\mathrm{eq}}=10^{-6.39} \\
K_{2}^{\mathrm{eq}}=10^{12.39} \\
K_{3}^{\mathrm{eq}}=10^{0.38} \\
K_{4}^{\mathrm{eq}}=10^{-1.5} \\
K_{5}^{\mathrm{eq}}=10^{-2.69} \\
K_{5}^{\mathrm{eq}}=10^{-2.54} \\
K_{5}^{\mathrm{eq}}=10^{-3.06} \\
K_{5}^{\mathrm{eq}}=10^{1.06}\end{array}$ \\
\hline Mineral reactions & $\begin{array}{l}\text { Solubility pro- } \\
\text { duct }\end{array}$ \\
\hline 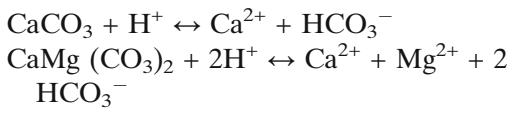 & $\begin{array}{l}K_{1}^{\mathrm{sp}}=10^{6.41} \\
K_{2}^{\mathrm{sp}}=10^{2.53}\end{array}$ \\
\hline Ion exchange reactions & Selectivity coefficient \\
\hline $\begin{array}{l}\mathrm{Na}^{+}+0.5 \mathrm{Ca}-X_{2} \leftrightarrow 0.5 \mathrm{Ca}^{2+}+\mathrm{Na}-\mathrm{X} \\
\mathrm{Na}^{+}+0.5 \mathrm{Mg}-X_{2} \leftrightarrow 0.5 \mathrm{Mg}^{2+}+\mathrm{Na}-X\end{array}$ & $\begin{array}{l}K_{1}^{\prime}=10^{0.67} \\
K_{2}^{\prime}=10^{0.67}\end{array}$ \\
\hline
\end{tabular}

$$
\begin{aligned}
K_{\mathrm{Na} / \mathrm{Ca}} & =\frac{\left[a\left(\mathrm{Ca}^{2+}\right)\right]^{1 / 2} a(\mathrm{Na}-X)}{a\left(\mathrm{Na}^{+}\right)\left[a\left(\mathrm{Ca}-X_{2}\right)\right]^{1 / 2}} \\
K_{\mathrm{Na} / \mathrm{Mg}} & =\frac{\left[a\left(\mathrm{Mg}^{2+}\right)\right]^{1 / 2} a(\mathrm{Na}-X)}{a\left(\mathrm{Na}^{+}\right)\left[a\left(\mathrm{Mg}-X_{2}\right)\right]^{1 / 2}}
\end{aligned}
$$

where $a$ is the activity. It is difficult to evaluate the activity coefficients of $\mathrm{Na}-X, \mathrm{Ca}-X_{2}$ and $\mathrm{Mg}$ $X_{2}$, and thus, selectivity coefficients are used instead of equilibrium constants according to the ThomasGaines convention (Appelo and Postma 2005). Rewriting Eqs. 20 and 21 in terms of the selectivity coefficients results in:

$$
\begin{aligned}
K_{\mathrm{Na} / \mathrm{Ca}}^{\prime} & =\frac{\zeta(\mathrm{Na}-X)\left[m\left(\mathrm{Ca}^{2+}\right)\right]^{0.5}}{\left[\zeta\left(\mathrm{Ca}-X_{2}\right)\right]^{0.5} m\left(\mathrm{Na}^{+}\right)} \cdot \frac{\left[\gamma\left(\mathrm{Ca}^{2+}\right)\right]^{0.5}}{\gamma\left(\mathrm{Na}^{+}\right)} \\
K_{\mathrm{Na} / \mathrm{Mg}}^{\prime} & =\frac{\zeta(\mathrm{Na}-X)\left[m\left(\mathrm{Mg}^{2+}\right)\right]^{0.5}}{\left[\zeta\left(\mathrm{Mg}-X_{2}\right)\right]^{0.5} m\left(\mathrm{Na}^{+}\right)} \cdot \frac{\left[\gamma\left(\mathrm{Mg}^{2+}\right)\right]^{0.5}}{\gamma\left(\mathrm{Na}^{+}\right)}
\end{aligned}
$$

where $\zeta\left[i-X_{a}\right]\left(i=\mathrm{Na}^{+}, \mathrm{Ca}^{2+}\right.$ or $\mathrm{Mg}^{2+}$ and $a$ is the valency) is the ion exchange equivalent fraction on the exchanger, $m$ is the molality and $\gamma$ is the activity coefficient. An important property of the exchanger is its cation exchanger capacity (CEC), which describes the number of ions that can be adsorbed on its surface. The moles of all components in GEM $^{\mathrm{TM}}$ are expressed as moles per grid-block bulk volume, $N$. Thus, if $V$ is the bulk volume of the rock, the total moles of the exchangeable components $(\mathrm{Na}-X$, $\mathrm{Mg}-X_{2}$ and $\left.\mathrm{Ca}-X_{2}\right)$ would be $\mathrm{VN}_{(i-X a)}$. Equation (24) must, therefore, be satisfied for a given value of CEC in the grid block:

$$
\mathrm{VN}_{\mathrm{Na}-X_{2}}+2 \mathrm{VN}_{\mathrm{Ca}-X_{2}}+2 \mathrm{VN}_{\mathrm{Mg}-X_{2}}=V \phi(\mathrm{CEC})
$$

Table 1 shows all the intra-aqueous, mineral and ion exchange reactions used in the modeling of LSWF, while the various species used in the simulations are provided in Table 2. It should be noted that cation exchange was used to model the coreflood experiments, which is mostly attributed to the presence of clay or sandstones. However, Zhang et al. $(2006,2007)$ asserted that $\mathrm{Ca}^{2+}$ and $\mathrm{Mg}^{2+}$ are potential determining ions during LSWF and are also involved in the ion exchange process. During the modeling, it was observed that all the anion exchange occurred during seawater injection, and the exchange of cations $\left(\mathrm{Ca}^{2+}\right.$ and $\left.\mathrm{Mg}^{2+}\right)$ was responsible for the incremental recovery during LSWF. As such, cation exchange was selected as the 
Table 2. List of the aqueous, solid and exchange species used in coreflood simulations

\begin{tabular}{ll}
\hline Species & \multicolumn{1}{c}{ Elements } \\
\hline Independent aqueous species & $\mathrm{H}^{+}, \mathrm{OH}^{-}, \mathrm{Ca}^{2+}, \mathrm{Mg}^{2+}, \mathrm{Cl}^{-}, \mathrm{CH}_{3} \mathrm{COO}^{-}, \mathrm{Na}^{+}, \mathrm{HCO}_{3}^{-}, \mathrm{SO}_{4}{ }^{2-}$ \\
Dependent aqueous species & $\mathrm{NaCl}, \mathrm{H}_{2} \mathrm{O}, \mathrm{CaSO}_{4}, \mathrm{MgSO}_{4}, \mathrm{CO}_{2}, \mathrm{CaCH}_{3} \mathrm{COO}^{+}$ \\
Solid species & $\mathrm{CaCO}_{3}, \mathrm{CaMg}_{\left(\mathrm{CO}_{3}\right)_{2}}$ \\
Exchange species & $\mathrm{Na}^{+}, \mathrm{Ca}^{2+}, \mathrm{Mg}^{2+}$ \\
\hline
\end{tabular}

multi-component ion exchange mechanism for modeling the coreflood experiments.

\section{Relative Permeability and Capillary Pressure}

Relative permeability is a very important parameter for history matching. The Brooks-Corey relative permeability correlation was used to obtain the relative permeability curves used in the modeling studies (Brooks and Corey 1964):

$$
\begin{gathered}
k_{\mathrm{rw}}\left(s_{w}\right)=k_{\mathrm{rw}}^{o} s_{\mathrm{wn}}^{n_{w}} \\
k_{\mathrm{ro}}\left(s_{w}\right)=k_{\mathrm{ro}}^{o}\left(1-s_{\mathrm{wn}}\right)^{n_{o}} \\
s_{\mathrm{wn}}=\frac{s_{w}-s_{\mathrm{wir}}}{1-s_{\mathrm{wir}}-s_{\mathrm{or}}}
\end{gathered}
$$

where $k_{\text {ro }}^{o}$ and $k_{\mathrm{rw}}^{o}$ are the endpoint relative permeabilities, $s_{\mathrm{wn}}$ is the normalized water saturation, $s_{\text {wir }}$ is the irreducible water saturation, $s_{\text {or }}$ is the residual oil saturation. $n_{o}$ and $n_{w}$ are the power law parameters for oil and water, respectively, known as Corey exponents.

The effect of capillary pressure on the simulation results and history matching of coreflood data was considered for LSWF. Initially, a constant pressure and saturation are defined for all grid blocks. As the different fluids are injected, both the pressure and saturation change. The Skjaeveland et al. (2000) capillary pressure correlation was used to model capillary pressure effects on the history match results. The correlations are given in Eqs. 28 and 29 for oil-wet and mixed-wet conditions, respectively:

$$
\begin{gathered}
P_{c}=\frac{c_{o}}{\left(\frac{S_{o}-S_{\mathrm{or}}}{1-S_{\mathrm{or}}}\right)^{a_{o}}} \\
P_{c}=\frac{c_{w}}{\left(\frac{S_{w}-S_{\mathrm{wir}}}{1-S_{\mathrm{wir}}}\right)^{a_{W}}}+\frac{c_{o}}{\left(\frac{S_{o}-S_{\mathrm{or}}}{1-S_{\mathrm{or}}}\right)^{a_{O}}}
\end{gathered}
$$

where $c_{w}, c_{o}, a_{w}$ and $a_{o}$ are constants for water and oil, and $c_{w}$ and $c_{o}$ represent the entry pressures, whereas $a_{w}$ and $a_{o}$ account for the pore size distribution. Due to the lack of relative permeability measurements, the pressure drop at the end of each flood cycle was used to calculate the endpoint relative permeabilities.

\section{Wettability Alteration Modeling}

The change in wettability from more oil-wet to intermediate-wet conditions during LSWF is known as the reason for the observed increase in oil recovery from the coreflood experiments. Wettability alteration is modeled in terms of a change in the relative permeability where two separate relative permeability curves are defined: one for seawater (high salinity) and the other for low-salinity water. In the modeling study, multi-component ion exchange was assumed to be the main mechanism responsible for the change in wettability and is modeled using the ion exchange equivalent fraction of $\mathrm{Mg}^{2+}\left(\zeta\left[\mathrm{Mg}-X_{2}\right]\right)$ as the interpolant for the relative permeability curves. $\zeta\left[\mathrm{Mg}-X_{2}\right]$ represents the amount of $\mathrm{Mg}^{2+}$ that is adsorbed on the carbonate surface during the process.

It is assumed that the adsorption of divalent cations such as $\mathrm{Mg}^{2+}$ and $\mathrm{Ca}^{2+}$ from the injected brine onto the carbonate surface (resulting from the adsorption of $\mathrm{SO}_{4}{ }^{2-}$ during seawater injection) causes the change in wettability from more oil-wet to less oil-wet during LSWF and, thus, increase in oil recovery. Zhang et al. $(2006,2007)$ reported that there is a high tendency for $\mathrm{Mg}^{2+}$ to substitute $\mathrm{Ca}^{2+}$ on the rock surface at high temperatures (usually 90-110 ${ }^{\circ} \mathrm{C}$ ). Because the reservoir temperature is greater than $90^{\circ} \mathrm{C}$, the ion exchange equivalent fraction of $\mathrm{Mg}^{2+}$ was used as the interpolant. In the modeling studies, if $\zeta\left[\mathrm{Mg}-X_{2}\right]$ is less than or equal to 0.33 , oil-wet relative permeability curves are used whereas less oil-wet curves are used when $\zeta\left[\mathrm{Mg}-X_{2}\right]$ is greater than or equal to 0.43 . For $\zeta\left[\mathrm{Mg}-X_{2}\right]$ values between 0.33 and 0.43 , interpo- 
lation between the two curves is used. The relative permeability and capillary pressure curves are shown in Figures 1, 2 and 3. Corefloods 1 and 2 in the figures refer to coreflooding experiments done on four and three composite carbonate cores, respectively. A more detailed description of corefloods 1 and 2 is provided in the following the section.

\section{PROBLEM FORMULATION}

\section{Experimental Data}

Two coreflood experiments were performed by Alameri et al. (2015) on heterogeneous low-permeability carbonate cores. The carbonate cores used for the experiments were from two facies: Facies 5 and 6 of a Middle Eastern carbonate reservoir. The experiments aimed at investigating the viability of a hybrid low-salinity water-surfactant enhanced oil recovery process. In this paper, only the LSWF part of the experimental work is investigated in the modeling study.

The cores were first flooded with formation water at a rate of $0.1 \mathrm{ml} / \mathrm{min}$ so that the core is initially $100 \%$ saturated with brine. Oil was then injected into the cores at the same flow rate until irreducible water saturation was reached. The carbonate cores were then aged for 8 weeks at reservoir temperature and pressure for wettability restoration. After aging, the cores were flooded with synthetic seawater at a flow rate of $0.1 \mathrm{ml} / \mathrm{min}$ until residual oil saturation. Brines of different salinities (LS1, LS2 and LS3) were then injected to study the effect of low-salinity brine on wettability alteration and oil recovery. LS1, LS2 and LS3 brines were made by diluting the seawater twice, four times and fifty times, respectively. Five pore volumes (PV) were injected for each set of low-salinity water. Oil recovery and pressure drop for all the experiments were measured and recorded. More information about the experimental work can be found in Alameri et al. (2015).

\section{Simulation Study}

Two one-dimensional (1D) Cartesian grid systems consisting of $30 \times 1 \times 1$ and $40 \times 1 \times 1$ grid blocks were used to model the two coreflood experiments by Alameri et al. (2015). A sensitivity study was done to determine the number of grid blocks to be used for each coreflood study; to ensure the physics of the process is properly captured while optimizing the simulation run-time. The composite of four cores from Facies 5 was discretized into 40 grid blocks, whereas that from Facies 6 (three composite cores) was discretized into 30 grid blocks. Ten grid blocks were used to represent each part of the composite cores, and the dimensions were chosen such that experimental measurements are honored. The 40-grid-block and 30-grid-block models are, respectively, known as corefloods 1 and 2 . Heterogeneity in porosity and permeability is captured by the composite nature of the cores used for the experiments.

Based on X-ray diffraction, the predominant mineral is calcite with minor occurrences of dolomite. Volume fractions of $75 \%$ and $5 \%$ were, therefore, used for calcite and dolomite, respectively. The mineral volume fraction does not sum up to $100 \%$ because it is believed that a small fraction of the rock is not involved in the ion exchange process (Awolayo and Sarma 2017). The properties of the reservoir cores and simulation models are presented in Tables 3 and 4. The porosity and permeability used in the simulation models were the same as reported from the experimental work; hence, they are only reported in Table 4. The properties and compositions of the fluids are given in Tables 5 and 6 . Figure 4 shows the porosity and permeability distributions for the two coreflood models.

A horizontal configuration was used for the simulation models, similar to the configurations used in the experiments, with two vertical wells: an injector and a producer. Rate control was used for the injection well with a constant injection rate of $0.1 \mathrm{ml} / \mathrm{min}\left(1.44 \times 10^{-4} \mathrm{~m}^{3} /\right.$ day $)$ in both cases. Based on the dimensions of the cores used in the simulation runs, one PV is equivalent to 0.34 and 0.23 day of injection for corefloods 1 and 2, respectively. The producer was controlled using a minimum bottom-hole pressure, which was set at $1200 \mathrm{kPa}$. The initial water saturation was set at 0.18 and 0.20 for corefloods 1 and 2, respectively.

\section{RESULTS AND DISCUSSION}

Several modeling cases were built, and simulations were performed to history-match the experimental results of oil recovery and pressure drop 


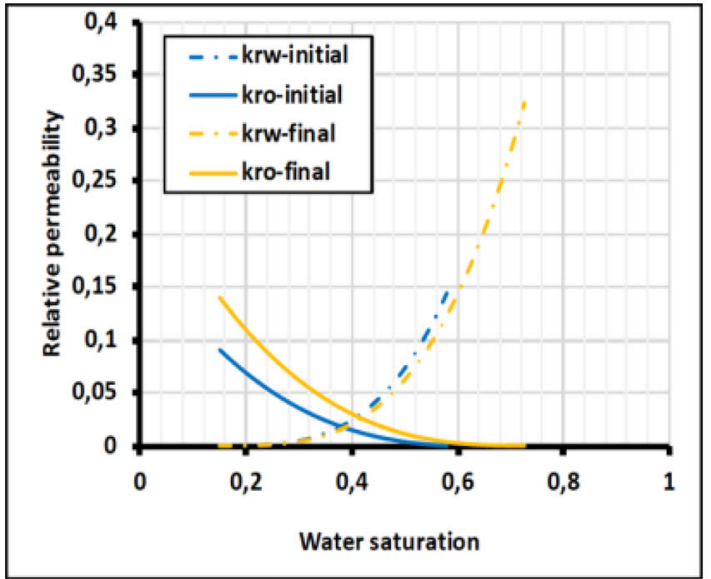

(a) Coreflood 1

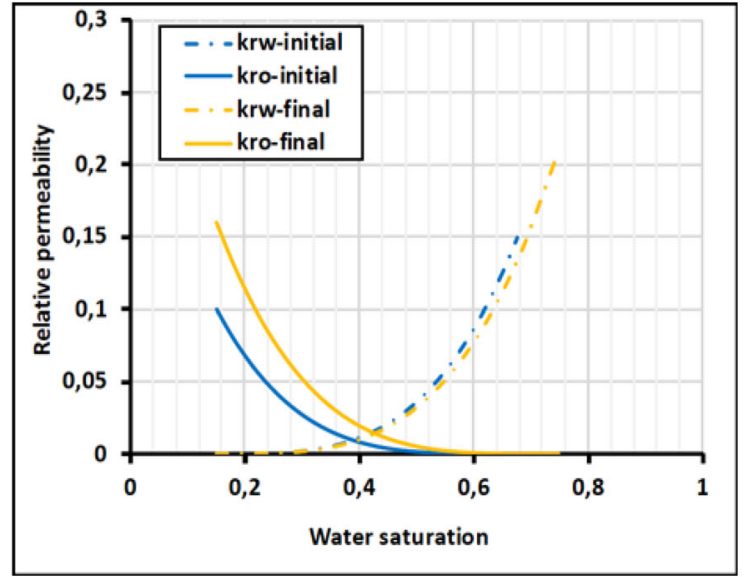

(b) Coreflood 2

Figure 1. Oil-water relative permeability curves for the two corefloods.

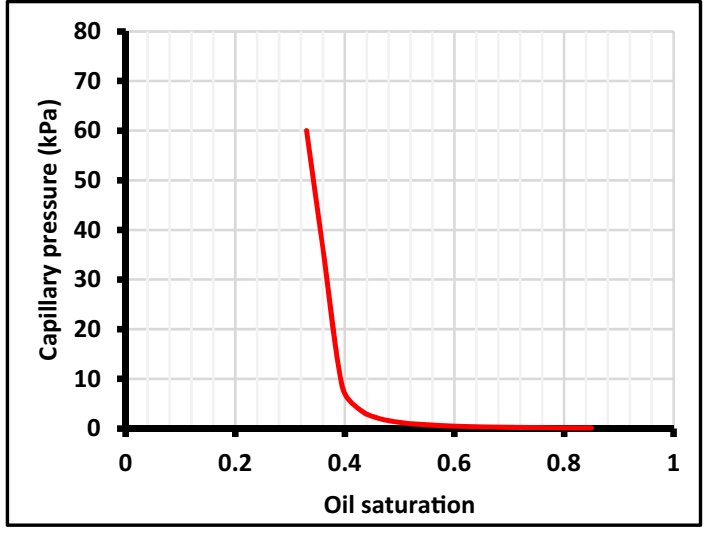

(a) Initial Imbibition capillary pressure curve

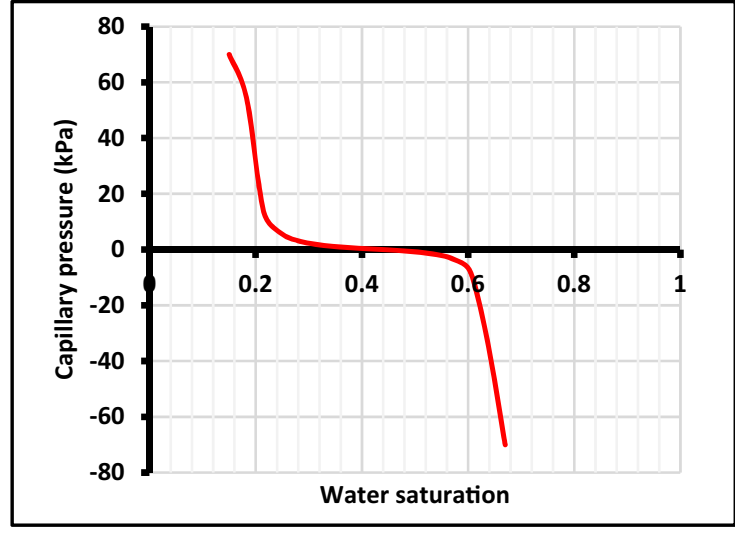

(b) Final imbibition capillary pressure curve

Figure 2. Initial and final imbibition capillary pressure curves for coreflood 1 showing a change in wettability from oil-wet to mixed-wet.

from the two coreflood experiments. The relative permeability and capillary pressure curves shown in Figures 1, 2 and 3 depict wettability change from oilwet during seawater (SW) injection to intermediatewet after LSWF. The crossover changes from 0.39 to 0.44 and 0.43 for corefloods 1 and 2, respectively.

Figures 5 and 6 show the results of the best history match obtained for oil recovery and pressure drop for the two coreflood simulations. The simulation results are in very good agreement with the experimental results, especially when capillary pressure is included in the model. The figures also show that capillary pressure has a greater effect on the pressure drop than the oil recovery, which is in line with the observations of Adegbite et al. (2018). The history-match parameters for relative permeability and capillary pressure are given in Table 7, while the geochemical history-match parameters are summarized in Table 8.

As shown in Table 6, the concentration of $\mathrm{SO}_{4}{ }^{2-}$ in $\mathrm{SW}$ is about 5 times the concentration in the initial formation water $(\mathrm{FW})$. The higher concentration increased the amount of $\mathrm{SO}_{4}{ }^{2-}$ adsorbed on the exchanger on the carbonate surface during SW injection, and this led to the desorption of oil from the rock surface. This also increased the CEC of the rock and subsequently the co-adsorption of $\mathrm{Mg}^{2+}$ as shown in Figure 7. $\mathrm{Mg}^{2+}$ was exchanged 


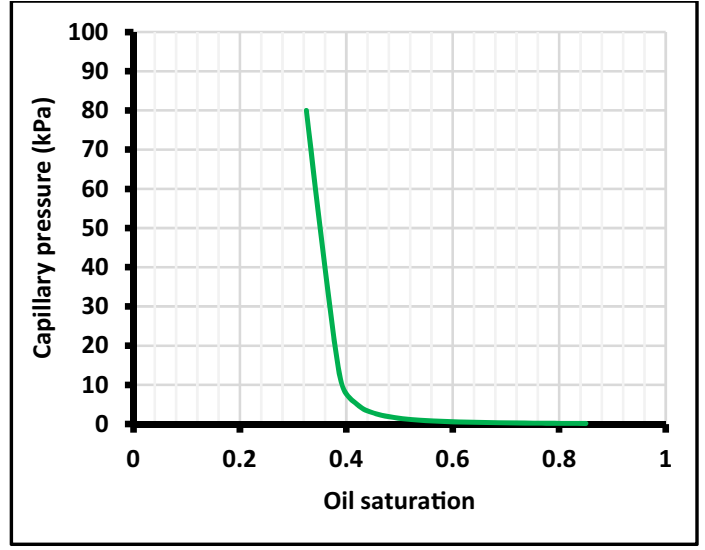

(a) Initial Imbibition capillary pressure curve

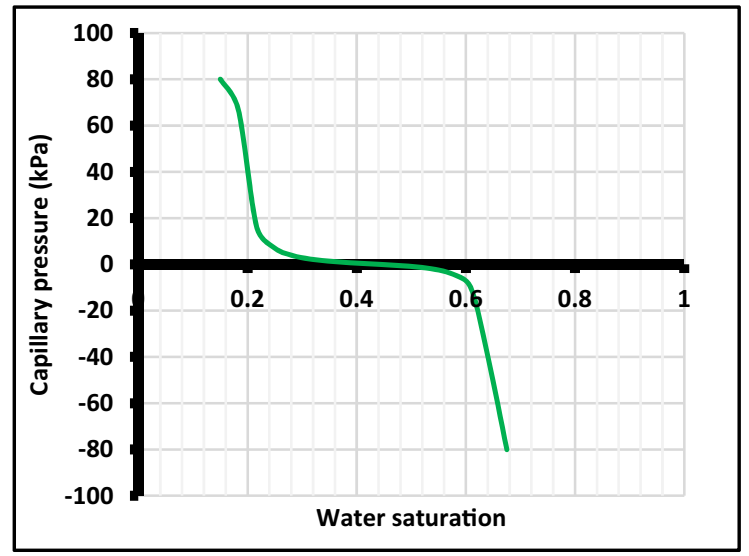

(b) Final imbibition capillary pressure curve

Figure 3. Initial and final imbibition capillary pressure curves for coreflood 2 showing a change in wettability from oil-wet to mixed-wet.

Table 3. Dimensions of reservoir cores. Adapted from Alameri et al. (2015)

\begin{tabular}{lll}
\hline Core properties & Facies-5 cores & Facies-6 cores \\
\hline Length, $L(\mathrm{~cm})$ & 4.17 & - \\
& 8.27 & 4.95 \\
& 4.62 & 4.60 \\
& 4.82 & 3.84 \\
Diameter, $D(\mathrm{~cm})$ & 3.81 & \\
Cross-sectional Area, $A\left(\mathrm{~cm}^{2}\right)$ & 11.40 & \\
\hline
\end{tabular}

The diameter, $\mathrm{D}$, and cross-sectional area, A, are the same for both cases
Table 5. Fluid properties used in the simulations. Adapted from Alameri et al. (2015)

\begin{tabular}{lcll}
\hline Fluid & Viscosity $(\mathrm{cP})\left(@ 90.6{ }^{\circ} \mathrm{C}\right)$ & ${ }^{\circ} \mathrm{API}$ & $\mathrm{pH}$ \\
\hline Oil & 3.00 & 32 & \\
FW & 0.54 & - & 7.17 \\
SW & 0.54 & - & 6.60 \\
LS1 & 0.54 & - & 6.53 \\
LS2 & 0.54 & - & 6.31 \\
LS3 & 0.54 & - & 6.00 \\
\hline
\end{tabular}

Table 4. Petrophysical properties of the simulation models

\begin{tabular}{|c|c|c|}
\hline Model description & Coreflood 1 & Coreflood 2 \\
\hline Model dimensions (1D) & $40 \times 1 \times 1$ & $30 \times 1 \times 1$ \\
\hline \multirow{5}{*}{ Grid-block sizes (m) } & $\Delta x_{1}=0.004$ & $\Delta x_{1}=0.004$ \\
\hline & $\Delta x_{2}=0.008$ & $\Delta x_{2}=0.008$ \\
\hline & $\Delta x_{3}=0.005$ & $\Delta x_{3}=0.005$ \\
\hline & $\Delta x_{4}=0.005$ & $\Delta y=\Delta z=0.034$ \\
\hline & $\Delta y=\Delta z=0.032$ & 32.490 \\
\hline Pore volume $\left(\mathrm{cm}^{3}\right)$ & 49.320 & $\Phi_{1}=0.238$ \\
\hline \multirow[t]{4}{*}{ Porosity $(\Phi)$} & $\Phi_{1}=0.269$ & $\Phi_{2}=0.227$ \\
\hline & $\Phi_{2}=0.246$ & $\Phi_{3}=0.174$ \\
\hline & $\Phi_{3}=0.207$ & $K_{x 1}=3.380$ \\
\hline & $\Phi_{4}=0.145$ & $K_{x 2}=1.180$ \\
\hline \multirow[t]{4}{*}{ Permeability $(\mathrm{mD})\left(K_{x}=K_{y}=K_{z}\right)$} & $K_{x 1}=3.380$ & $K_{x 3}=0.696$ \\
\hline & $K_{x 2}=2.250$ & \\
\hline & $K_{x 3}=1.160$ & \\
\hline & $K_{x 4}=0.696$ & \\
\hline
\end{tabular}

during SW injection until equilibrium was reached (i.e., when the ion exchange equivalent fraction of $\mathrm{Mg}^{2+}$ remained constant). During LSWF, no further adsorption of $\mathrm{SO}_{4}{ }^{2-}$ occurred, because of the high $\mathrm{SO}_{4}{ }^{2-}$ adsorption happened earlier during $\mathrm{SW}$ injection. However, the carbonate surface site was 
Table 6. Compositions of brines used in the simulations. Adapted from Teklu et al. (2017)

\begin{tabular}{|c|c|c|c|c|c|c|}
\hline Brine/Conc. (ppm) & $\mathrm{Na}^{+}$ & $\mathrm{Ca}^{2+}$ & $\mathrm{Mg}^{2+}$ & $\mathrm{Cl}^{-}$ & $\mathrm{SO}_{4}{ }^{2-}$ & TDS \\
\hline FW & $32,439.5$ & 6118.1 & 1229.7 & $65,202.0$ & 869.6 & $107,013.8$ \\
\hline SW & $12,986.1$ & 691.5 & 3459.0 & $30,110.6$ & 4098.8 & $51,346.0$ \\
\hline LS1 & 6495.1 & 346.0 & 1729.5 & $15,058.7$ & 2049.8 & $25,679.0$ \\
\hline LS2 & 3247.6 & 173.0 & 864.9 & 7529.7 & 1024.9 & $12,840.0$ \\
\hline LS3 & 259.8 & 13.7 & 69.2 & 602.1 & 82.1 & 1027.0 \\
\hline
\end{tabular}

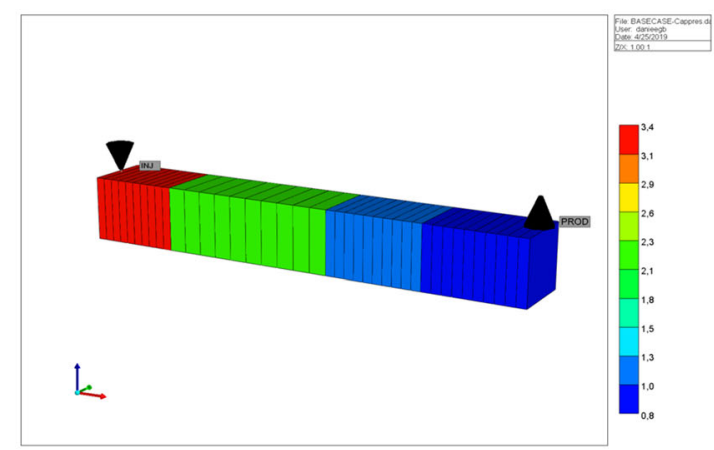

(a) Permeability distribution for model 1

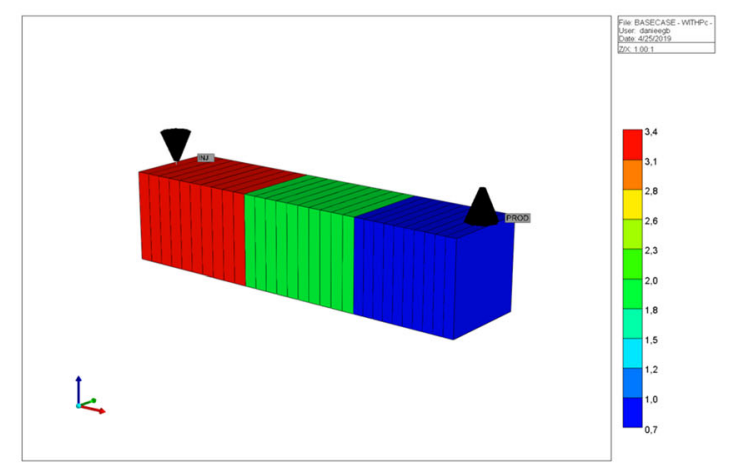

(c) Permeability distribution for model 2

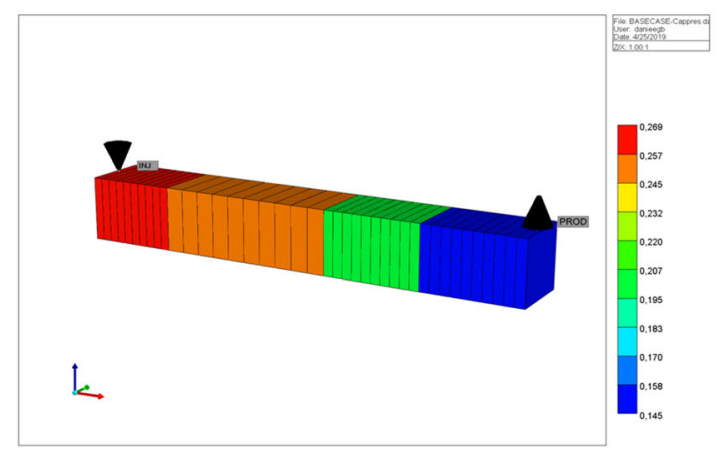

(b) Porosity distribution for model 1

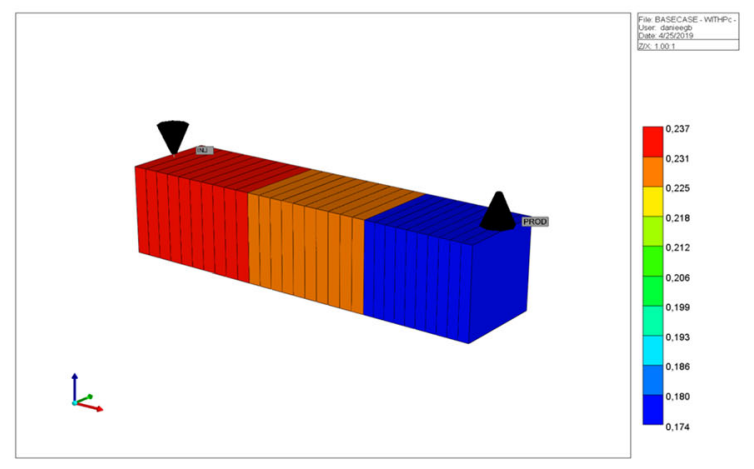

(d) Porosity distribution for model 2

Figure 4. Simulation models with heterogeneous porosity and permeability.

still open to more cation exchange, and thus the exchange of $\mathrm{Mg}^{2+}$ and $\mathrm{Ca}^{2+}$ continued until equilibrium was reached at each injection stage.

The ion exchange equivalent fractions for different grid blocks are shown in Figure 7. The amount of $\mathrm{Mg}^{2+}$ exchanged on the surface site was higher than that of $\mathrm{Ca}^{2+}$, and this could be the reason for the improved recovery. Additionally, the figure shows that because LS3 brine was injected, further adsorption of $\mathrm{Mg}^{2+}$ occurred only in the injection well grid block. In other grid blocks, desorption of $\mathrm{Mg}^{2+}$ from carbonate surface took place.
On the other hand, there was significant adsorption of $\mathrm{Ca}^{2+}$ in all the grid blocks. Desorption of $\mathrm{Mg}^{2+}$ and adsorption of $\mathrm{Ca}^{2+}$ were most likely the reason why no further increase in oil recovery was observed from the experiments after the injection of LS3 brine.

The adsorption of $\mathrm{Mg}^{2+}$ and $\mathrm{Ca}^{2+}$ decreased the amounts of the ions present in the aqueous phase and this resulted in the dissolution of calcite. The dissolution of calcite increased the amount of $\mathrm{Ca}^{2+}$ in solution and caused the precipitation of dolomite (Fig. 8). However, calcite dissolution was about one 


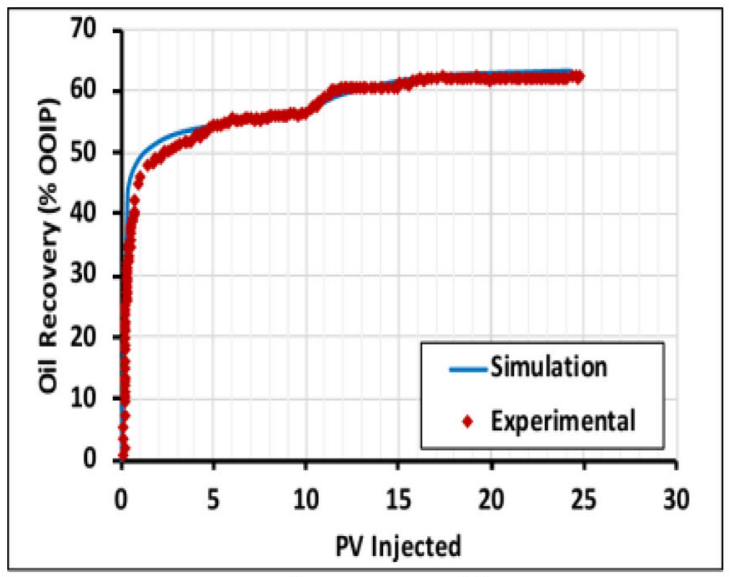

(a) Oil recovery with no Pc

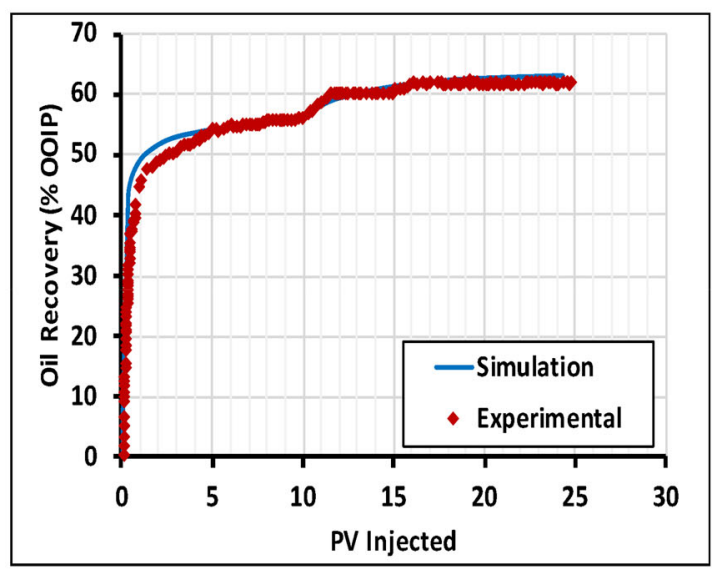

(c) Oil recovery with $\mathrm{Pc}$

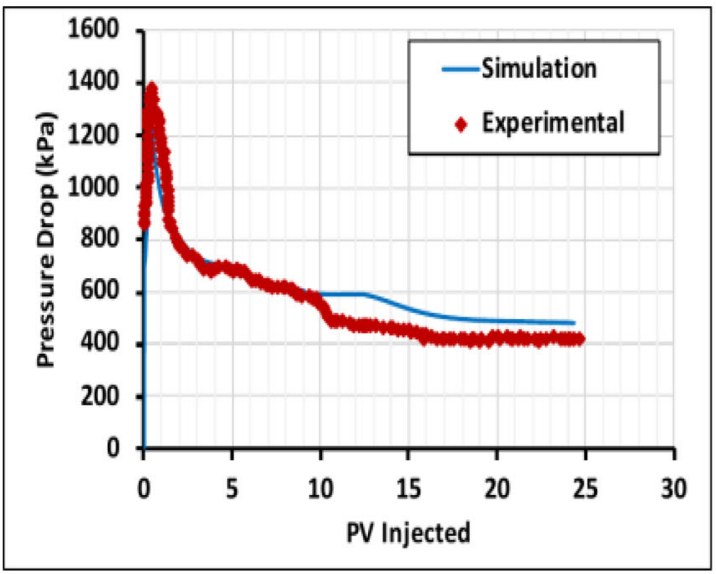

(b) Pressure drop with no Pc

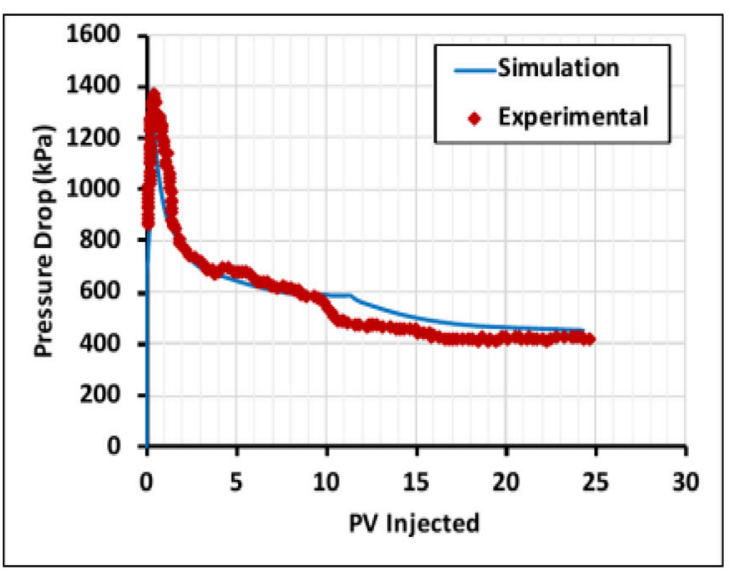

(d) Pressure drop with Pc

Figure 5. History match of oil recovery and pressure drop for coreflood 1, with and without capillary pressure.

order of magnitude higher than dolomite precipitation. This could have led to an increase in the porosity and permeability and subsequently an increase in oil recovery. However, the magnitude of calcite dissolution was believed to be quite small (in the order of $10^{-4}$ ) to have any significant effect on oil recovery in this case.

Decreases in the effluent concentrations of $\mathrm{Mg}^{2+}, \mathrm{Ca}^{2+}, \mathrm{SO}_{4}{ }^{2-}, \mathrm{Na}^{+}$and $\mathrm{Cl}^{-}$were reported from the experimental work, and the same trend was observed from the simulations (Fig. 9). The increase in the effluent concentration of $\mathrm{Ca}^{2+}$ in Figure 9, toward the end of the injection cycle, was because of an increase in $\mathrm{Ca}^{2+}$ adsorption during the period of LS3 brine flooding as previously discussed. The increase in $\mathrm{Ca}^{2+}$ adsorption increased the rate of calcite dissolution, resulting in an increase in the effluent concentration of $\mathrm{Ca}^{2+}$. The effluent concentration of $\mathrm{Mg}^{2+}$ also increased toward the end because of a decrease in dolomite precipitation.

It is also worth noting that $\mathrm{Na}^{+}$and $\mathrm{Cl}^{-}$were considered non-active ions and were not expected to play a role in the process (Awolayo and Sarma 2017). Because $\mathrm{Na}^{+}$and $\mathrm{Cl}^{-}$were neither present in seawater nor in any of the low-salinity brines, the $\mathrm{Na}^{+}$and $\mathrm{Cl}^{-}$in the effluent were from the formation water. The small dips at the start of each injection stage were because of the ion exchange that took place between the injected brine and exchanger on the carbonate surface. Shaik et al. (2019) investigated the effect of brine type and ionic strength on the wettability alteration of naphthenic-acid-adsorbed calcite surfaces and observed that irrespective of the salt type, the wettability of the 


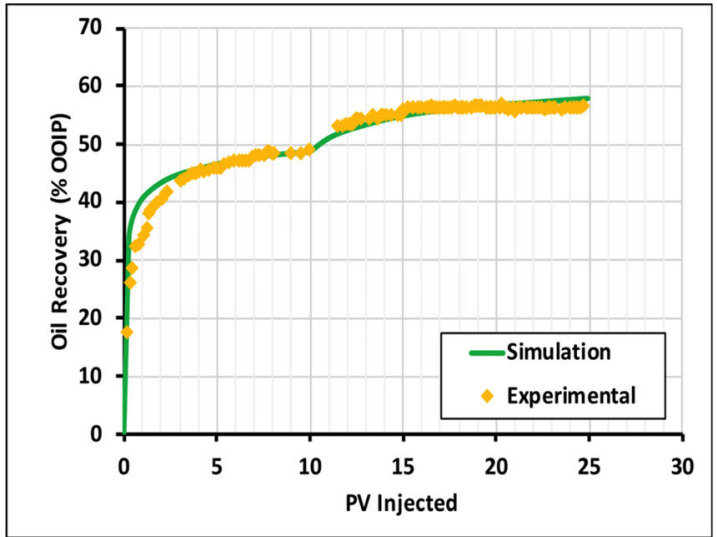

(a) Oil recovery with no Pc

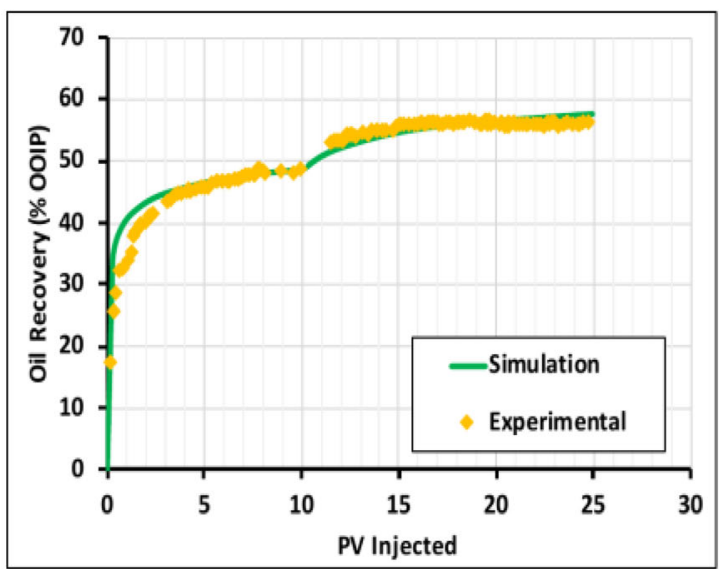

(c) Oil recovery with Pc

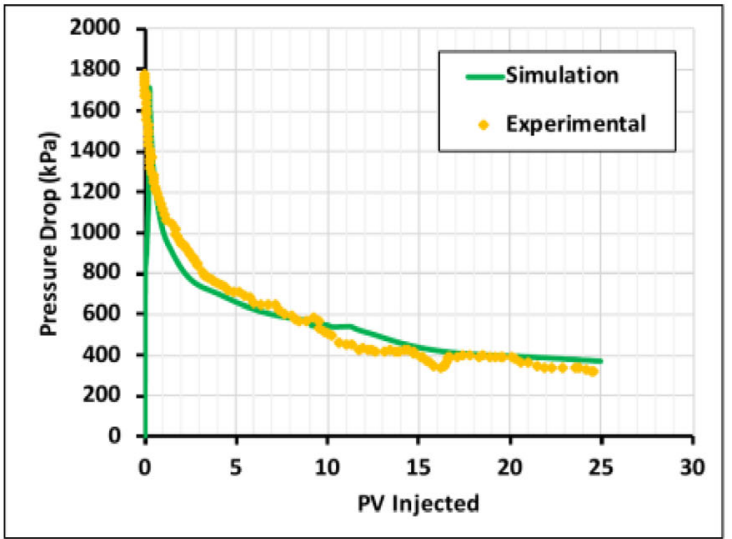

(b) Pressure drop with no Pc

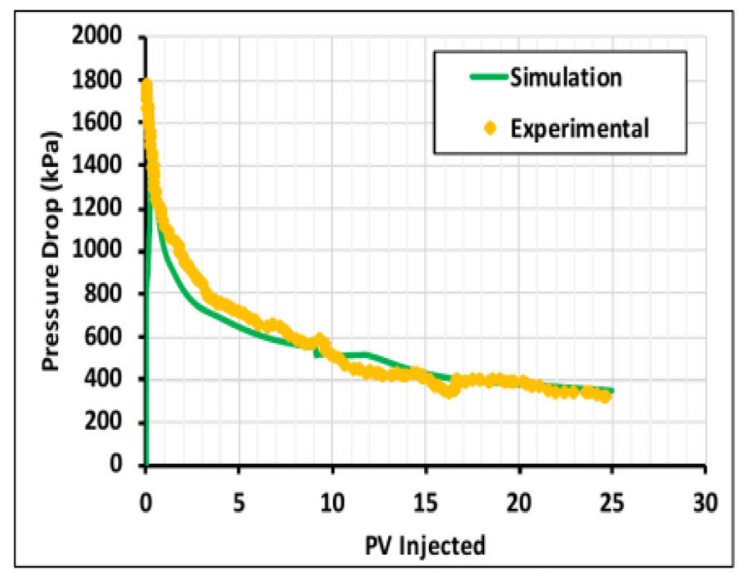

(d) Pressure drop with Pc

Figure 6. History match of oil recovery and pressure drop for coreflood 2, with and without capillary pressure.

Table 7. Relative permeability parameters used for history matching

\begin{tabular}{lcc}
\hline & Coreflood 1 & Coreflood 2 \\
\hline Relative permeability & & \\
$k_{\mathrm{rw}}^{*}$ & 0.27 & 0.15 \\
$k_{\mathrm{ro}}^{*}$ & 0.09 & 0.10 \\
$n_{w}$ & 3.30 & 3.50 \\
$n_{o}$ & 2.70 & 3.90 \\
Capillary pressure & & \\
$C_{w}$ & 0.08 & 0.10 \\
$C_{o}$ & -0.08 & -0.10 \\
$a_{w}=a_{o}$ & 2.00 & 2.00 \\
\hline
\end{tabular}

naphthenic-acid-adsorbed calcite surfaces was altered from oil-wet to water-wet as the brine salinity decreased. However, it should be noted that their experiments were done using single-electrolyte
Table 8. Geochemistry parameters used for history matching

\begin{tabular}{ll}
\hline Exchange reactions parameters & \\
$\mathrm{CEC}$ & 80 \\
$K_{\mathrm{Na} / \mathrm{Ca}}^{\prime}$ & 0.67 \\
$K_{\mathrm{Na} / \mathrm{Mg}}$ & 0.58 \\
Interpolation parameter 1 & 0.33 \\
Interpolation parameter 2 & 0.43 \\
Mineral reactions & \\
Reactive surface area $\left(\mathrm{m}^{2} / \mathrm{m}^{3}\right)$ & 100 \\
Activation energy $\left(\mathrm{J} / \mathrm{mol}^{\prime}\right)$ & 41,870 \\
Reaction rate calcite $\left(\mathrm{mol} / \mathrm{m}^{2} \mathrm{~s}\right)$ & -6.80 \\
Reaction rate dolomite $\left(\mathrm{mol} / \mathrm{m}^{2} \mathrm{~s}\right)$ & -10.80 \\
\hline
\end{tabular}

brine-based solutions. We believe that in an electrolytic solution with various salts, the potential determining ions in carbonates are $\mathrm{CH}_{3} \mathrm{COO}^{-}$, $\mathrm{SO}_{4}{ }^{2-}, \mathrm{Ca}^{2+}$ and $\mathrm{Mg}^{2+}$. 

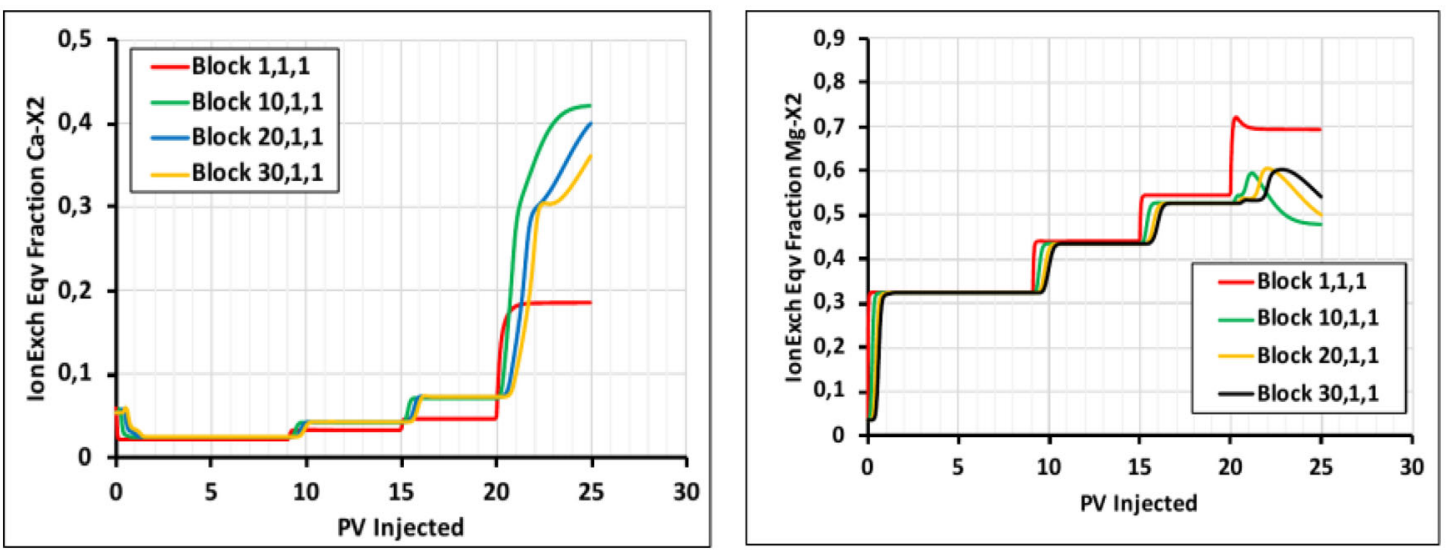

Figure 7. Ion-exchange equivalent fractions for different grid blocks.
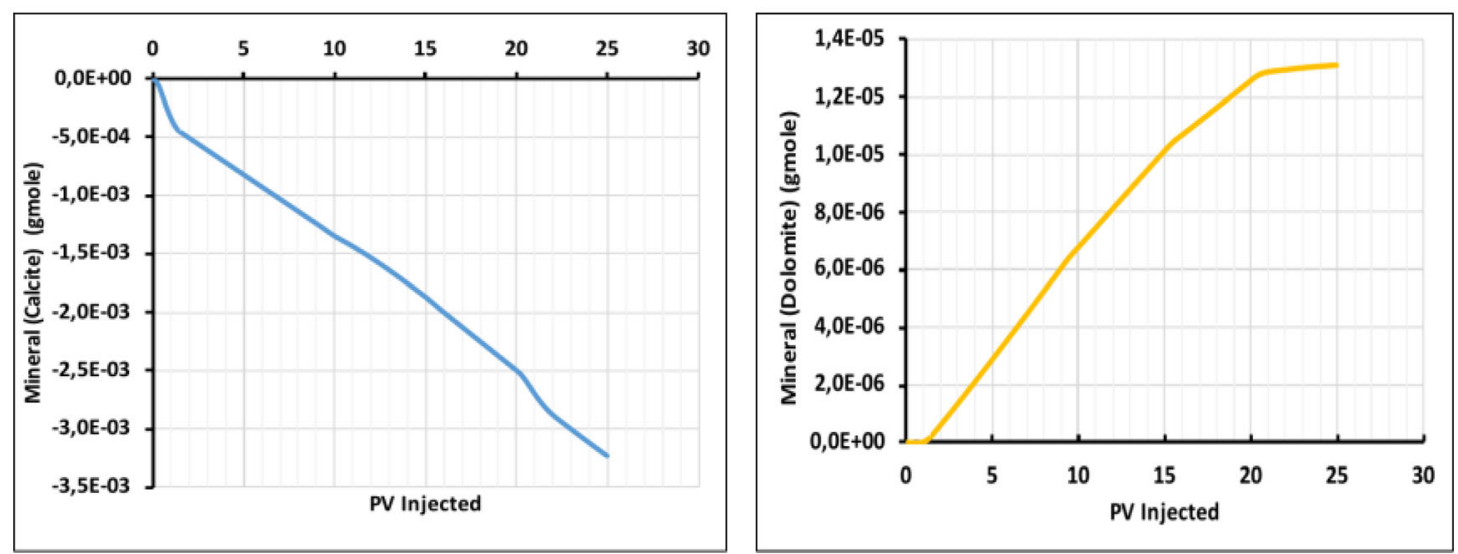

Figure 8. Changes in mineral moles of calcite and dolomite.

Figure 10 shows an increase in $\mathrm{pH}$ during the process. There was a sharp rise in the $\mathrm{pH}$ at the start of LS3 brine injection, after which the $\mathrm{pH}$ decreased to an equilibrium value. The behavior around 20-23 PVI was most likely due to a drastic change in the injected fluid (dilution from four to fifty times). This significantly affected the thermodynamic equilibrium of the system when the fluid was initially injected. However, after the injected fluid was given some time to interact with other fluids in the system, the system returned to its thermodynamic equilibrium state.

\section{SENSITIVITY STUDY}

Sensitivity analysis was applied to many key parameters, and the results are discussed in this section, in terms of oil recovery and ion exchange equivalent fractions.

\section{Timing of Low-Salinity Water Injection}

The effect of injecting low-salinity water in secondary mode compared to seawater injection has been investigated by some researchers (e.g., Zhang et al. 2006; Shaker Shiran and Skauge 2013). A comparison of oil recovery from LSWF in secondary and tertiary modes was studied by Zhang and Morrow (2006) based on their experiments on Berea sandstone cores. They concluded that improvement in oil recovery by LSWF is usually observed for both secondary and tertiary modes, but sometimes only for one or another. Shaker Shiran and Skauge (2013) 

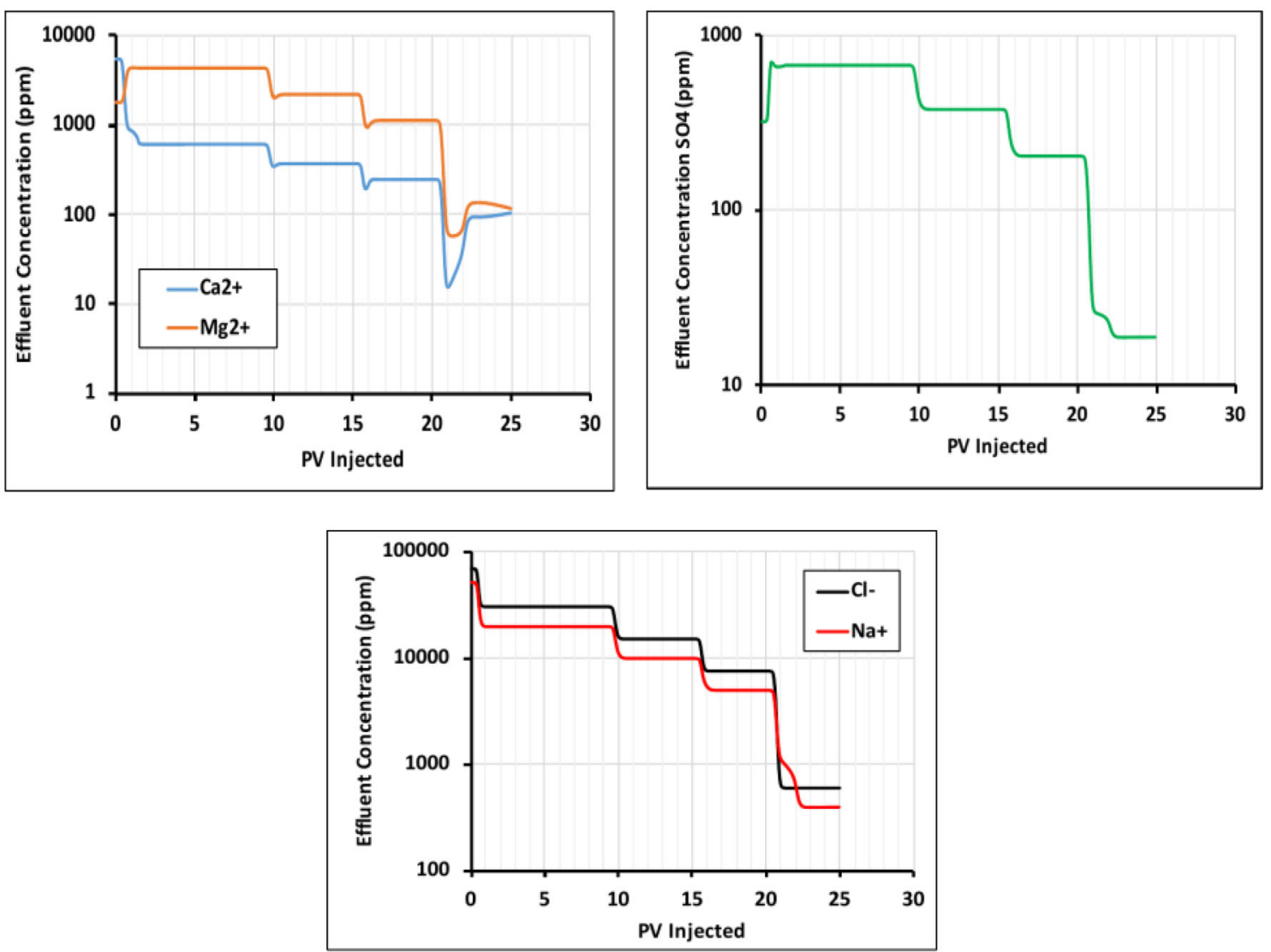

Figure 9. Effluent ions concentration.

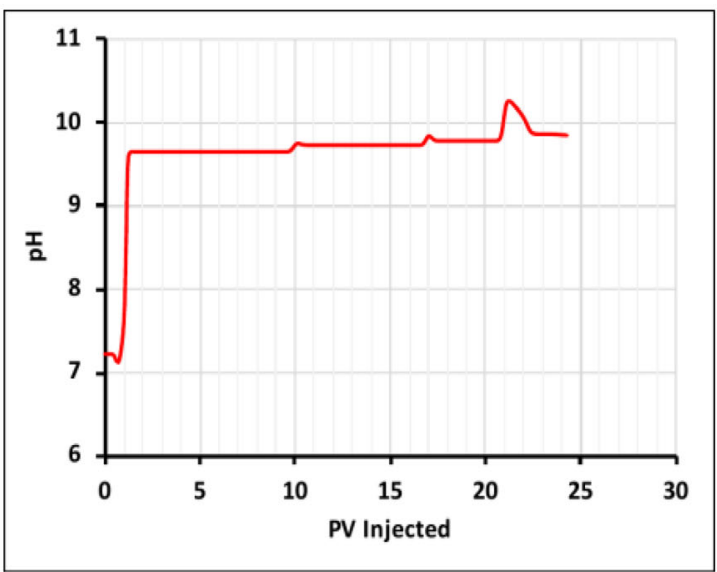

(a) Coreflood 1

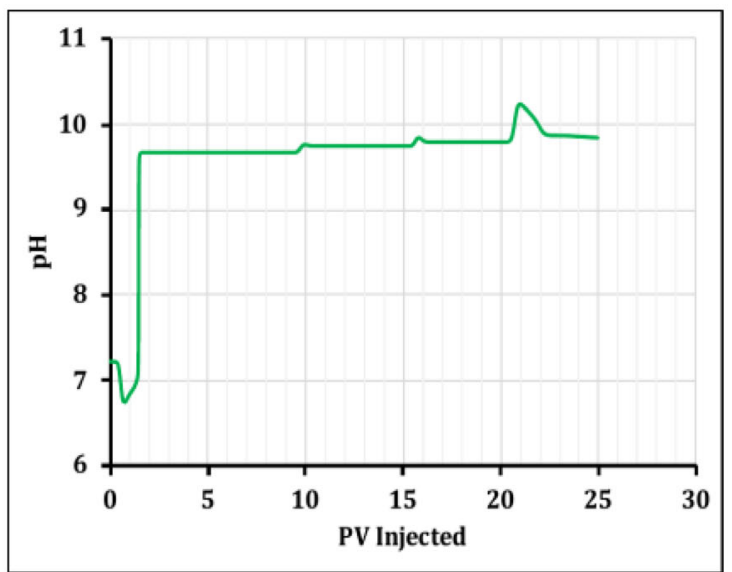

(b) Coreflood 2

Figure 10. Effluent $\mathrm{Ph}$.

reported positive response from injecting low-salinity water in secondary mode for water-wet and intermediate-wet Berea sandstone cores. They sug- gested that the higher oil recovery observed in secondary mode compared to tertiary mode by LSWF might be a result of effective trapping of oil clusters 
during high-salinity water injection in secondary mode, before LSWF is initiated in tertiary mode. The injection of low-salinity water at an early time might lead to more effective mobilization of oil by maintaining a continuous oil phase. In this paper, the effect of injecting low-salinity water in secondary and tertiary modes was investigated.

\section{Secondary-Mode LSWF}

Simulations were performed for three different cases. The first case involved only seawater injection, the second case involved injection of LS1 brine, and LS2 brine was injected in the third case. The three cases are known as SW, LS1 and LS2, respectively. In all three cases, 10 PVs were flooded with the respective fluids. The results of oil recovery and ion exchange equivalent fractions are presented in Figures 11 and 12, respectively. Figure 11 shows that the oil recovery for both LS1 and LS2 was the same despite different ion exchange equivalent fractions as shown in Figure 12. Wettability alteration was modeled using a change in relative permeability curves with the interpolation on the basis of the ion exchange equivalent fraction of $\mathrm{Mg}^{2+}$. However, when the ion exchange equivalent fraction surpassed a certain threshold, there was very little change in the relative permeability (or wettability) and hence insignificant change in the oil recovery. A summary of the results is given in Table 9 .

\section{Tertiary-Mode LSWF}

LSWF can be implemented in tertiary mode. The effect of injection interval size of high-salinity waterflooding and LSWF was investigated. Three different interval sizes were selected where the cores were first flooded with seawater and then with lowsalinity water.

The simulations were performed in such a way that a total of 15 PVs was flooded in each case. Six different scenarios (cases 1-6) were simulated for each of the corefloods; three with seawater and LS1 brine as the injection fluids, and the other three with seawater and LS2 brine. In case 1, 10 PVs were injected with SW followed by 5 PVs of LS1 brine, similar to the experimental procedure. Case 2 involved 7 PVs of SW injection and 8 PVs of LS1 injection. Five PVs and $10 \mathrm{PVs}$ are flooded with SW and LS1 brine in case 3, respectively. The same interval sizes were used accordingly for cases 4 to 6 . However, LS2 brine was injected instead of LS1 brine after SW injection. Figures 13 and 14 show the oil recovery and ion exchange equivalent fractions obtained from the simulations. The results are summarized in Table 10.

Figures 11 and 13 show that the earlier the onset of LSWF, the higher the final oil recovery. When low-salinity water was injected earlier, it had more time to interact with the reservoir rock and the fluids present. The salinity gradient due to the injection of low-salinity water into a high saline environment caused a disruption of the thermodynamic equilibrium and triggers the exchange of ionic species such as $\mathrm{SO}_{4}{ }^{2-}, \mathrm{Mg}^{2+}$ and $\mathrm{Ca}^{2+}$ between the injected brine and the crude oil/brine/rock system. This eventually led to wettability alteration and higher oil recovery (Zhang et al. 2006, 2007; Adegbite et al. 2018).

Figure 14 shows the ion exchange equivalent fractions of $\mathrm{Mg}^{2+}$ and $\mathrm{Ca}^{2+}$ for different cases of tertiary-mode LSWF. The concentration of $\mathrm{Ca}^{2+}$ in the FW was much higher than the concentration of $\mathrm{Mg}^{2+}$. Therefore, the original ion exchange equivalent fraction of $\mathrm{Ca}^{2+}$ was higher than $\mathrm{Mg}^{2+}$. Introduction of SW (higher concentration of $\mathrm{Mg}^{2+}$ and lower concentration of $\mathrm{Ca}^{2+}$ compared with $\mathrm{FW}$ ) resulted in the ion exchange equivalent fractions of $\mathrm{Mg}^{2+}$ and $\mathrm{Ca}^{2+}$ to increase and decrease, respectively. When LS1 or LS2 was injected, concentration of $\mathrm{Ca}^{2+}$ in the aqueous phase was low and this resulted in calcite dissolution. The released $\mathrm{Ca}^{2+}$ adsorbs and resulted in increased ion exchange equivalent fraction of $\mathrm{Ca}^{2+}$. However, high concentration of $\mathrm{Mg}^{2+}$ resulted in the precipitation of dolomite and increased ion exchange equivalent fractions of $\mathrm{Mg}^{2+}$. This explains the trend observed in Figure 14.

It should be noted that the increase in oil recovery was substantially higher when LSWF was implemented in secondary mode compared to tertiary, which is consistent with the observations of Shaker Shiran and Skauge (2013). In addition, Figure 13 and Table 10 show that LSWF with LS2 brine yield almost the same recovery as LSWF with LS1 brine both in secondary and tertiary modes. However, the water breakthrough (BT) time for the two cases differs, with BT occurring slightly earlier for LS2 brine injection. It is worth pointing out that these investigations were done at core scale, and the 


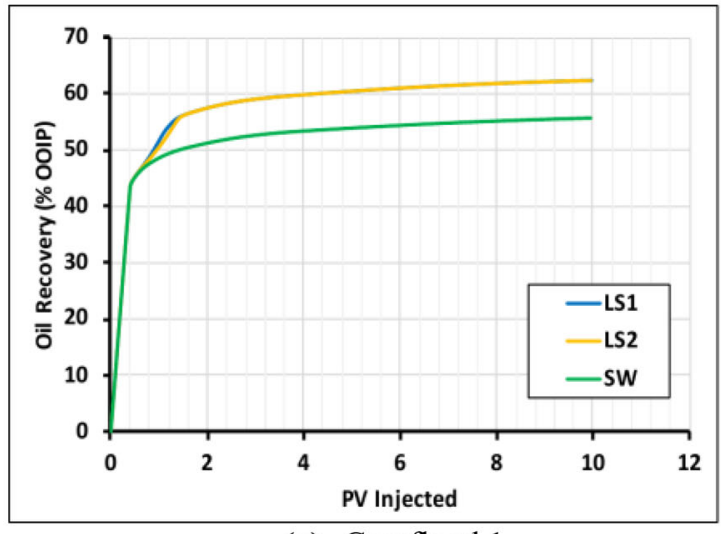

(a) Coreflood 1

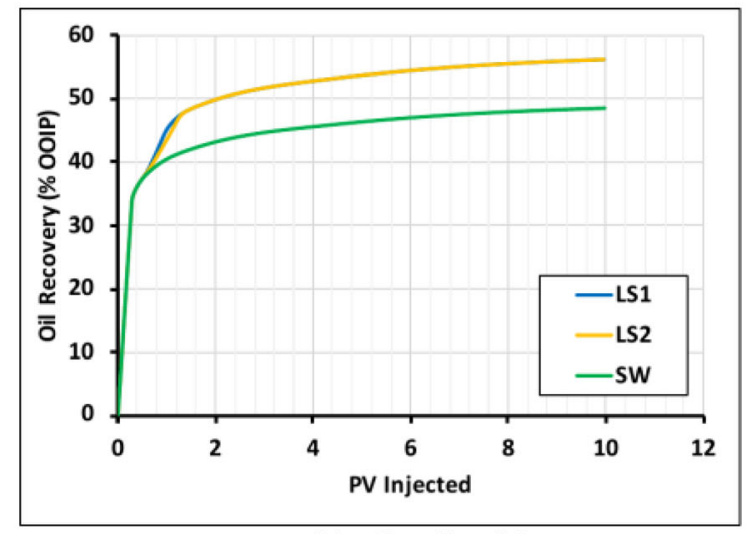

(b) Coreflood 2

Figure 11. Oil recovery comparison for secondary-mode LSWF and SW flooding.
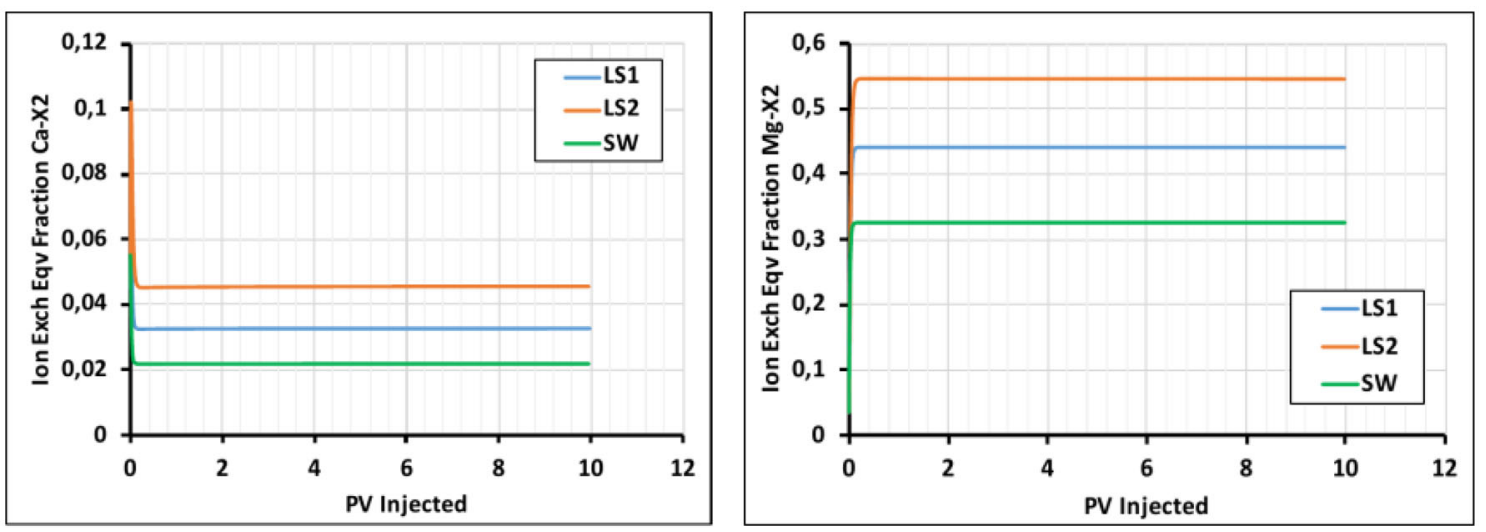

Figure 12. Ion exchange equivalent fraction of $\mathrm{Ca}^{2+}$ and $\mathrm{Mg}^{2+}$, Block $1,1,1$ for secondary-mode LSWF.

Table 9. Oil recovery comparison for secondary-mode LSWF and SW injection

\begin{tabular}{lcc}
\hline Injection scheme & \multicolumn{2}{c}{ Oil recovery $(\%$ OOIP $)$} \\
\cline { 2 - 3 } & Coreflood 1 & Coreflood 2 \\
\hline SW & 55.67 & 48.54 \\
LS1 & 62.50 & 56.20 \\
LS2 & 62.50 & 56.20 \\
\hline
\end{tabular}

increase at reservoir scale would probably be much less. Taking into account that the timing of LSWF might have associated additional costs, a thorough economic analysis was needed to compare the costs and benefits before a decision is made on when to implement LSWF.

\section{Injection Rate}

LSWF improves both physical and chemical displacements, unlike high-salinity waterflooding where physical displacement is mostly benefited (Srisuriyachai et al. 2016). Physical displacement occurred immediately as water injection began whereas chemical displacement began later due to the time needed for the ions in the brine to react with the rock surface. The injection rate was, therefore, a crucial parameter in optimizing the LSWF process. In this study, the effect of injection rate on oil recovery was investigated using three injection rates: 0.1 (base case), 0.045 and 0.5 ; all in $\mathrm{ml} / \mathrm{min}$. The results are summarized in Table 11.

Figure 15 shows that the higher the injection rate is, the higher the oil recovery is. At low injec- 


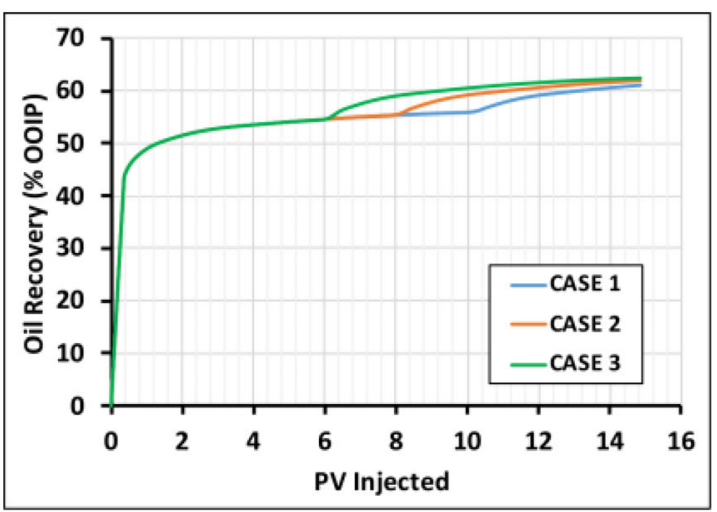

(a) Coreflood 1 - SW-LS1

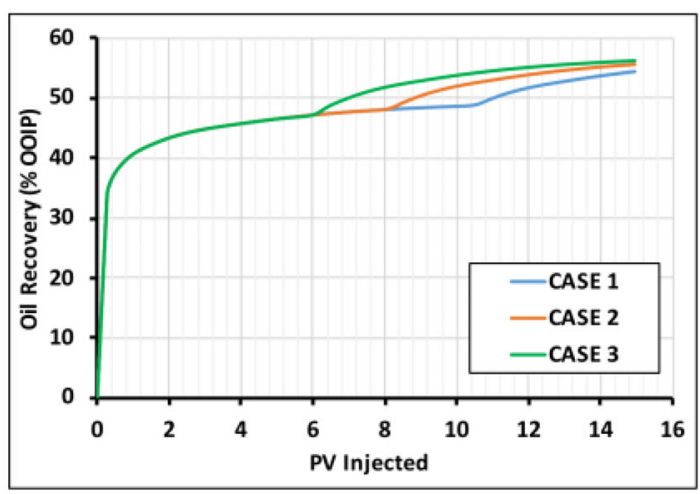

(c) Coreflood 2-SW- LS1

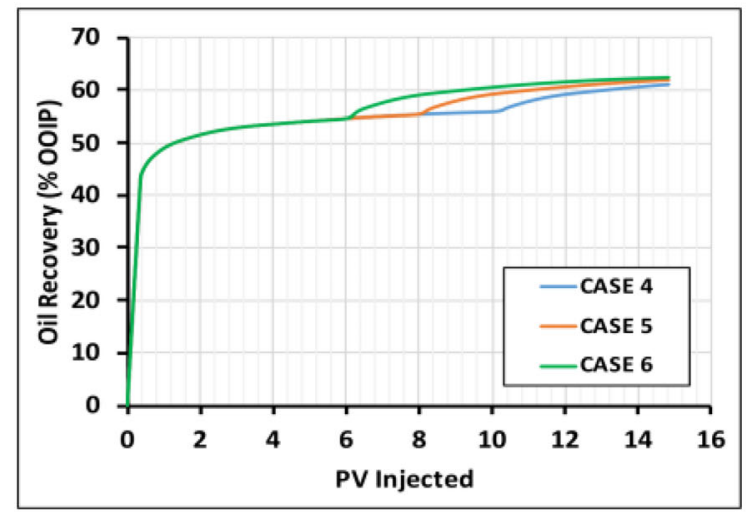

(b) Coreflood 1 - SW-LS2

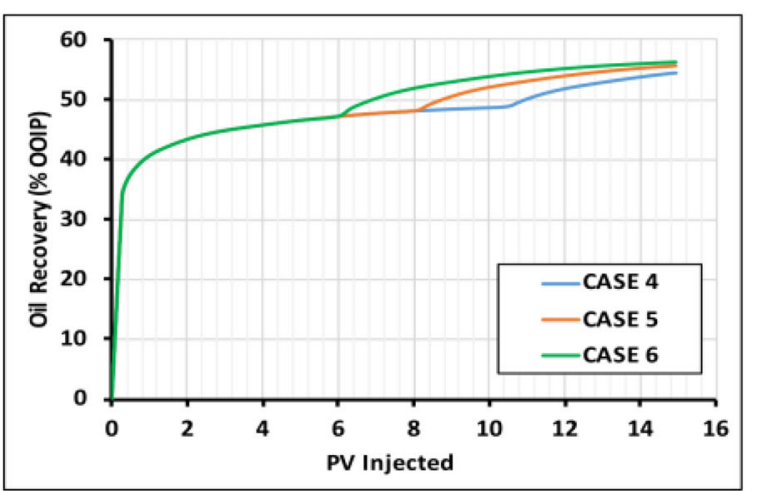

(d) Coreflood 2-SW- LS2

Figure 13. Oil recovery comparison for tertiary-mode LSWF.

tion rates, chemical displacement dominated while at high/moderate injection rates both physical and chemical displacements were favored, resulting in higher recovery. The effect of the injection rate on the ion exchange equivalent fractions of $\mathrm{Mg}^{2+}$ and $\mathrm{Ca}^{2+}$ is shown in Figure 16. Injection rate had little effect on geochemical interactions; thus, the increased oil recovery (with injection rate) was most likely due to a change in the contribution from physical displacement. The effect of higher injection rates (than the rates used in this study) is subject to further investigation.

\section{Injection Temperature}

The effect of temperature on LSWF was investigated using three different injection temperatures. The injection temperature was the same as the reservoir temperature $\left(90.6{ }^{\circ} \mathrm{C}\right)$ for the base case. In the second case, the injection temperature $\left(70{ }^{\circ} \mathrm{C}\right)$ was less than the reservoir temperature, and finally, the injection temperature $\left(110{ }^{\circ} \mathrm{C}\right)$ was higher than the reservoir temperature in the last case.

Figure 17 shows that there was very little change in the oil recovery as the injection temperature changes. This is because the oil recovery is primarily a function of the relative permeability interpolation, and no changes were made to the relative permeability interpolation in all three cases. However, some differences can be seen in the ion exchange equivalent fractions of $\mathrm{Mg}^{2+}$ and $\mathrm{Ca}^{2+}$, mineral behavior and $\mathrm{pH}$ (Figs. 18, 19, 20). Figure 18 shows that the injection temperature had a greater effect on the exchange of $\mathrm{Mg}^{2+}$ compared to $\mathrm{Ca}^{2+}$. This was probably because $\mathrm{Mg}^{2+}$ was the main cation responsible for the observed LSEs. Figure 19 shows that the injection temperature had a significant effect on mineral dissolution/precipitation. At lower injection temperatures, the changes in the moles of calcite and dolomite were smaller, because 


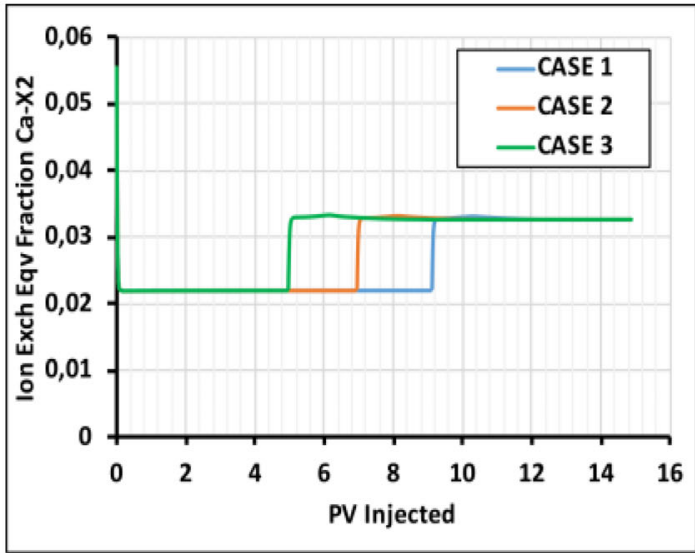

(a) SW- LS1

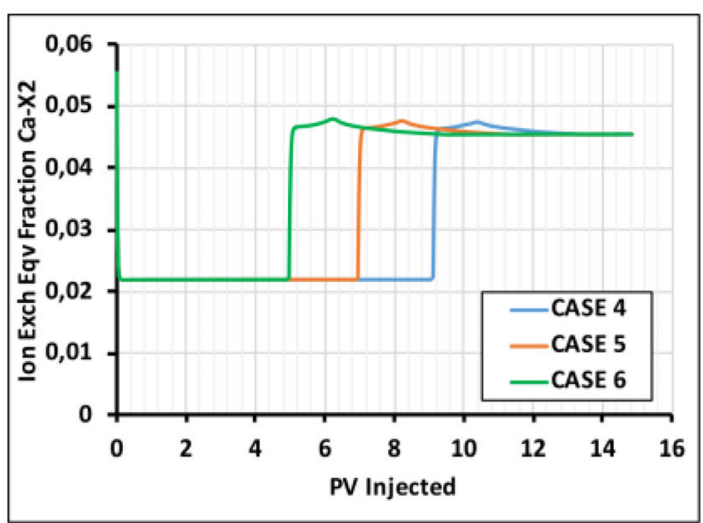

(c) SW- LS2

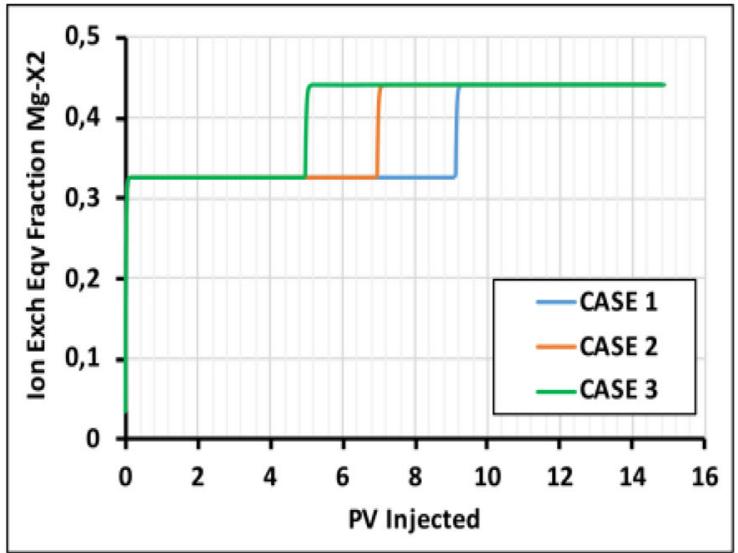

(b) SW- LS1

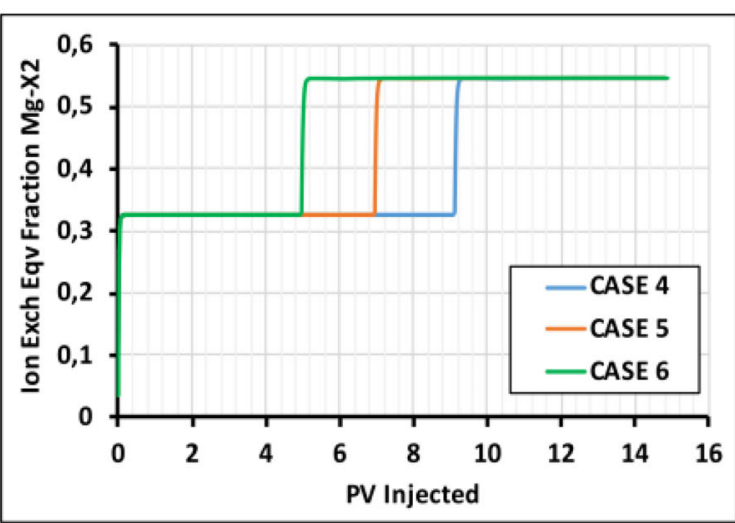

(d) SW- LS2

Figure 14. Ion-exchange equivalent fractions of $\mathrm{Ca}^{2+}$ and $\mathrm{Mg}^{2+}$, Block $1,1,1$ for tertiary-mode LSWF.

Table 10. Oil recovery results for three different HS-LS injection interval sizes

\begin{tabular}{lcc}
\hline Injection scheme & \multicolumn{2}{c}{ Oil recovery $(\%$ OOIP) } \\
\cline { 2 - 3 } & Coreflood 1 & Coreflood 2 \\
\hline CASE 1 & 60.06 & 54.44 \\
CASE 2 & 61.93 & 55.62 \\
CASE 3 & 62.41 & 56.24 \\
CASE 4 & 61.08 & 54.47 \\
CASE 5 & 61.94 & 55.64 \\
CASE 6 & 62.41 & 56.25 \\
\hline
\end{tabular}

the reaction rates were lower. The low reaction rates slowed down the ion exchange process, and no effect of LSWF on oil recovery is seen (Fig. 17). Figure 20 shows that temperature has a significant effect on
Table 11. Oil recovery results for three different injection rates

\begin{tabular}{lcc}
\hline Injection rate $(\mathrm{ml} / \mathrm{min})$ & \multicolumn{2}{c}{ Oil recovery $(\%$ OOIP) } \\
\cline { 2 - 3 } & Coreflood 1 & Coreflood 2 \\
\hline 0.1 -Base case & 63.10 & 57.69 \\
0.045 & 61.49 & 56.23 \\
0.5 & 64.54 & 60.45 \\
\hline
\end{tabular}

$\mathrm{pH}$, and this is due to the effect on mineral reactions. The results are summarized in Table 12 .

\section{Interpolation Routines}

Two additional mechanistic modeling methods were used in this study to investigate the ability of different methods to model the same process. The 


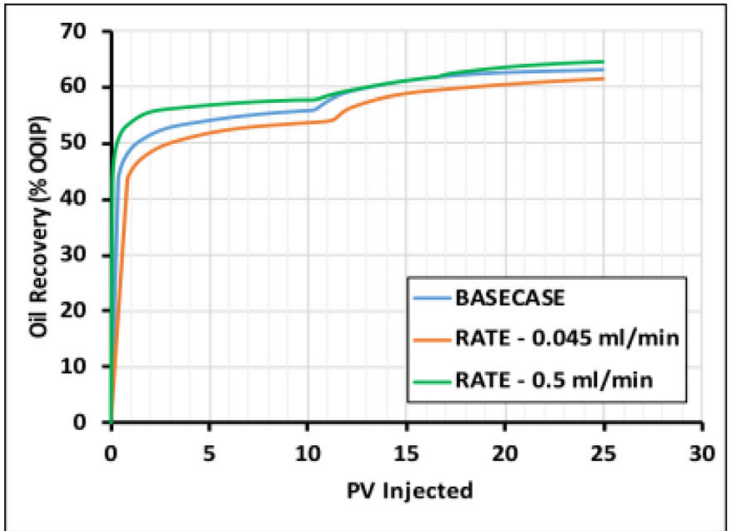

(a) Coreflood 1

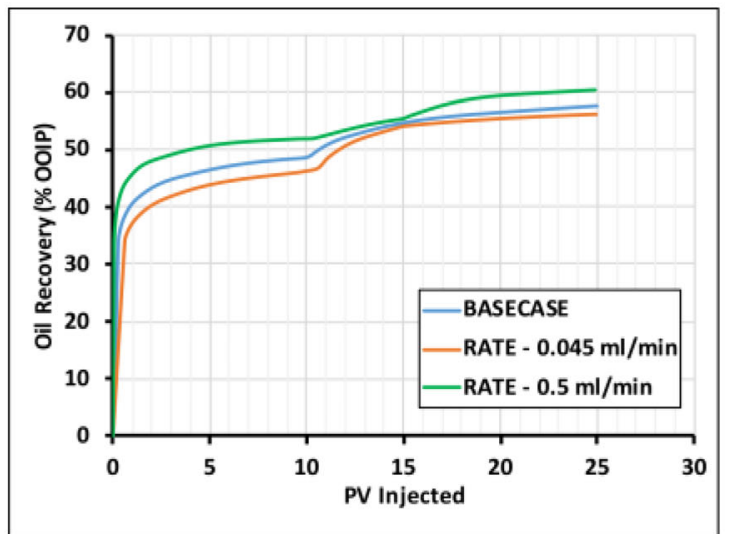

(b) Coreflood 2

Figure 15. Oil recovery as a function of injection rate.

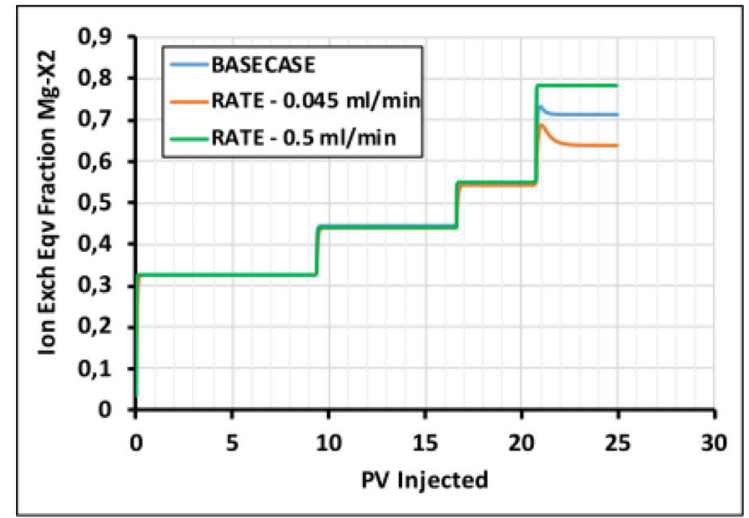

(a) Coreflood 1

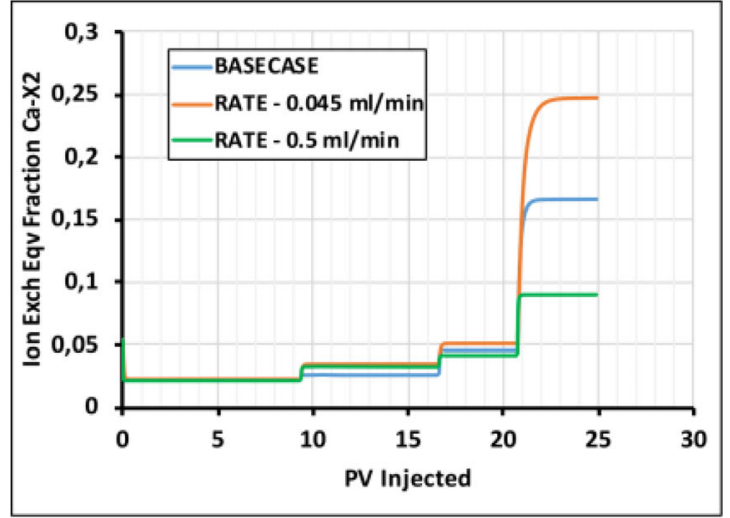

(b) Coreflood 2

Figure 16. Ion exchange equivalent fractions of $\mathrm{Ca}^{2+}$ and $\mathrm{Mg}^{2+}$, Block $1,1,1$ for different injection rates.

two methods involve relative permeability interpolations based on the anion exchange between the sulfate ion in the brine and the carboxylic ion in the oil, and the concentration of the sulfate ion in the aqueous phase. The anion exchange reaction between the injected brine and the exchanger on the carbonate rock surface is:

$$
\begin{aligned}
\mathrm{SO}_{4}^{2-}+ & 2 \mathrm{CH}_{3} \mathrm{COO}-X \leftrightarrow 2 \mathrm{CH}_{3} \mathrm{COO}^{-} \\
& +\mathrm{SO}_{4}-X_{2}
\end{aligned}
$$

The oil recovery for different methods is shown in Figure 21. This figure shows that the oil recovery profile is very sensitive to the interpolant used in the modeling. When the equivalent fraction of sulfate was used as the interpolant, no LSE was observed during LSWF. This was because all the anion ex- change between sulfate and carboxylic ion occurred within the first five pore volumes of the injection (i.e., during SW injection as shown in Figure 22).

When different low-salinity brines were injected, only the adsorption of divalent cations $\left(\mathrm{Mg}^{2+}\right.$ and $\mathrm{Ca}^{2+}$ ) took place. Because the equivalent fraction of $\mathrm{SO}_{4}{ }^{2-}$ was constant during LSWF, no change in oil recovery was observed. Although LSE was observed when the aqueous concentration of sulfate was used as the interpolant, the recovery profile that matches the experimental data was not obtained. The best match was obtained when the equivalent fraction of $\mathrm{Mg}^{2+}$ was used as the interpolant. The final oil recoveries from the three methods were, however, close to each other. Table 13 provides a summary of the results. 


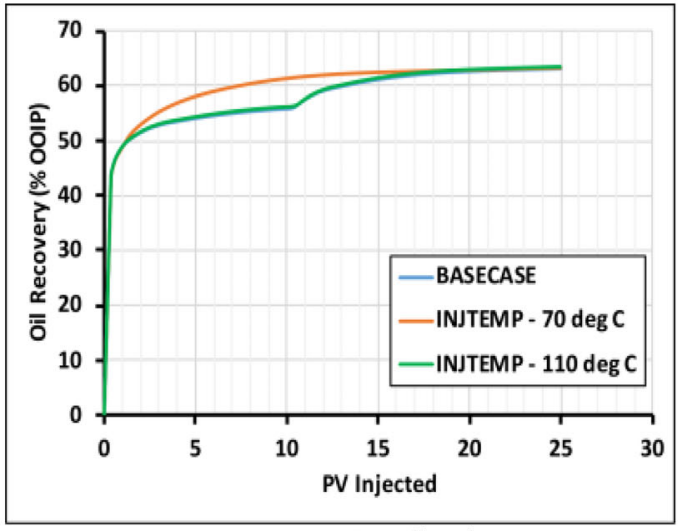

(a) Coreflood 1

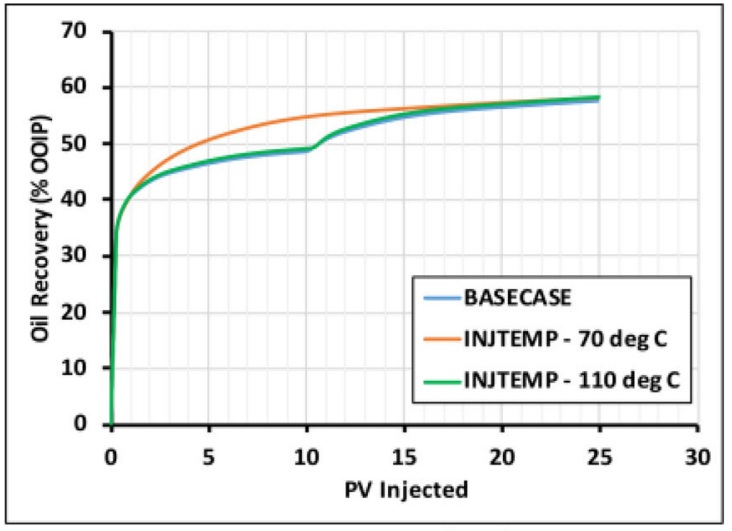

(b) Coreflood 2

Figure 17. Oil recovery as a function of injection temperature.

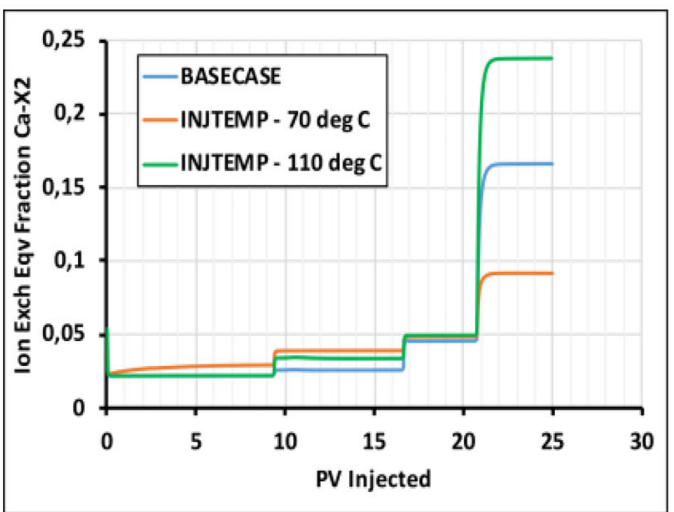

(a) Coreflood 1

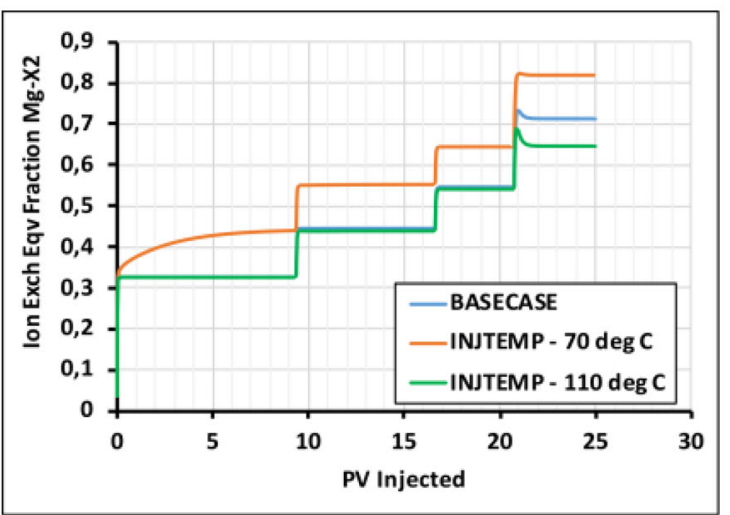

(b) Coreflood 2

Figure 18. Ion exchange equivalent fractions of $\mathrm{Ca}^{2+}$ and $\mathrm{Mg}^{2+}$, Block $1,1,1$ for different injection temperatures.
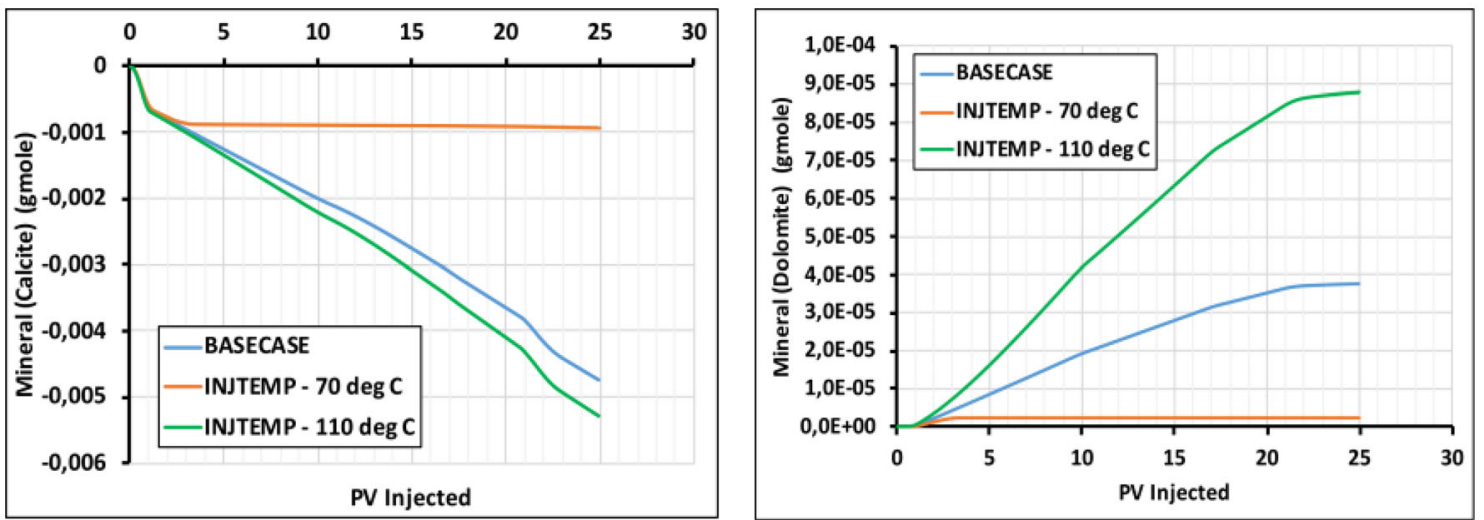

Figure 19. Changes in moles of calcite and dolomite for different injection temperatures. 


\section{CONCLUSIONS}

This study investigated the geochemical modeling of LSWF. A history match of laboratory data from coreflood experiments on heterogeneous lowpermeability carbonate cores was performed using the compositional reservoir simulator $\mathrm{GEM}^{\mathrm{TM}}$ by CMG. Sensitivity analysis was performed on some

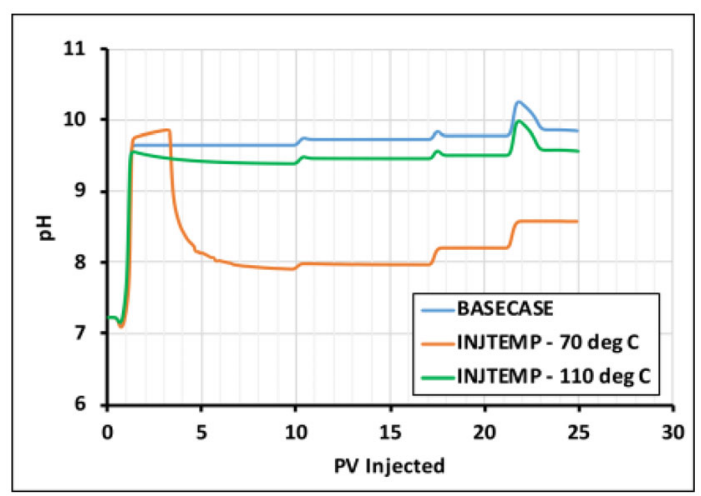

Figure 20. Effluent $\mathrm{pH}$.

Table 12. Oil recovery results for three different injection temperatures

\begin{tabular}{lcc}
\hline Injection temperature $\left({ }^{\circ} \mathrm{C}\right)$ & \multicolumn{2}{c}{ Oil recovery $(\%$ OOIP $)$} \\
\cline { 2 - 3 } & Coreflood 1 & Coreflood 2 \\
\hline 90.6 -Base case & 63.10 & 57.69 \\
70 & 63.24 & 58.21 \\
100 & 63.44 & 58.32 \\
\hline
\end{tabular}

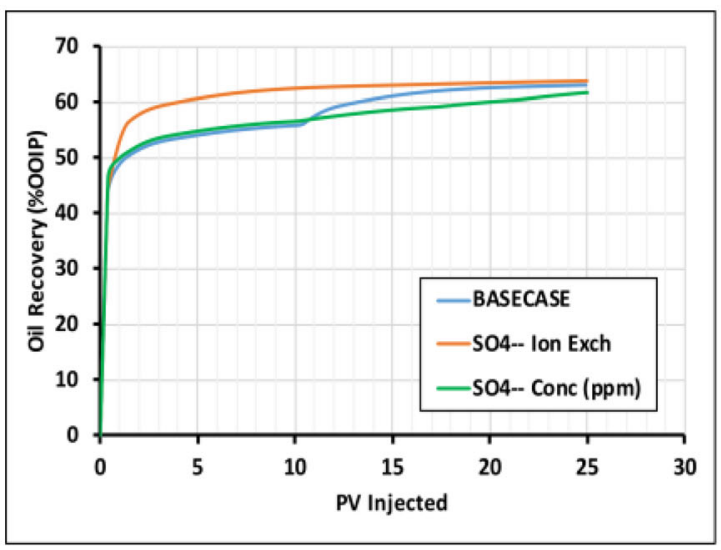

key parameters to evaluate their effects on the results. The following conclusions can be drawn:

- Multi-component ion exchange involving $\mathrm{SO}_{4}{ }^{2-}, \mathrm{CH}_{3} \mathrm{COO}^{-}, \mathrm{Ca}^{2+}$ and $\mathrm{Mg}^{2+}$ between the injected brine and the carbonate rock surface is identified as the main mechanism responsible for wettability alteration and the observed increase in oil recovery during LSWF for the coreflood simulations. Capillary pressure has a significant effect on history matching of experimental pressure drop during LSWF and should be included in the modeling.

- The timing of LSWF has a significant effect on oil recovery. The earlier the onset of LSWF, the more the oil recovery is enhanced because the low-salinity brine has more time to interact with the reservoir rock and fluids.

- Different mechanistic models can be used in modeling the LSWF. The ability to history match the experimental data strongly depends on the mechanistic modeling method used. It is, therefore, imperative that the correct mechanism is selected when modeling the process.

- Benefits from LSWF are from a combination of both physical and chemical displacement processes, which make the injection rate a very important parameter in the process. Temperature effects on mineral and ion exchange reactions can also be significant and should be included in the modeling process.

Figure 21. Oil recovery as a function of the mechanistic modeling method.

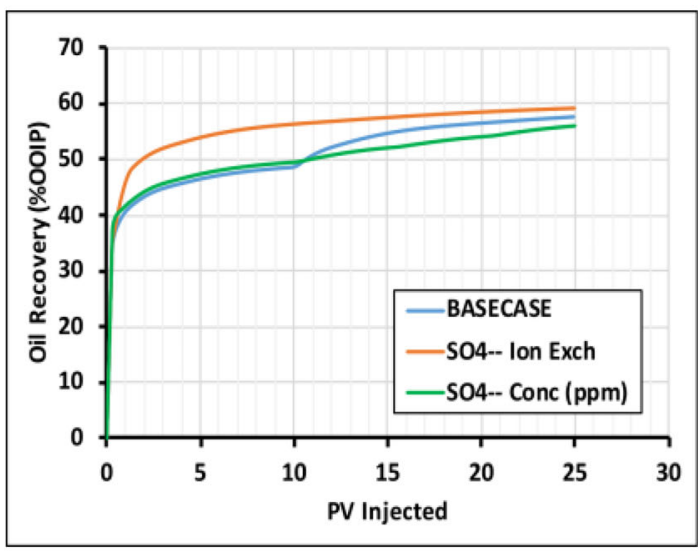

21. Oil recovery as a function of the mechanistic modeling method. 

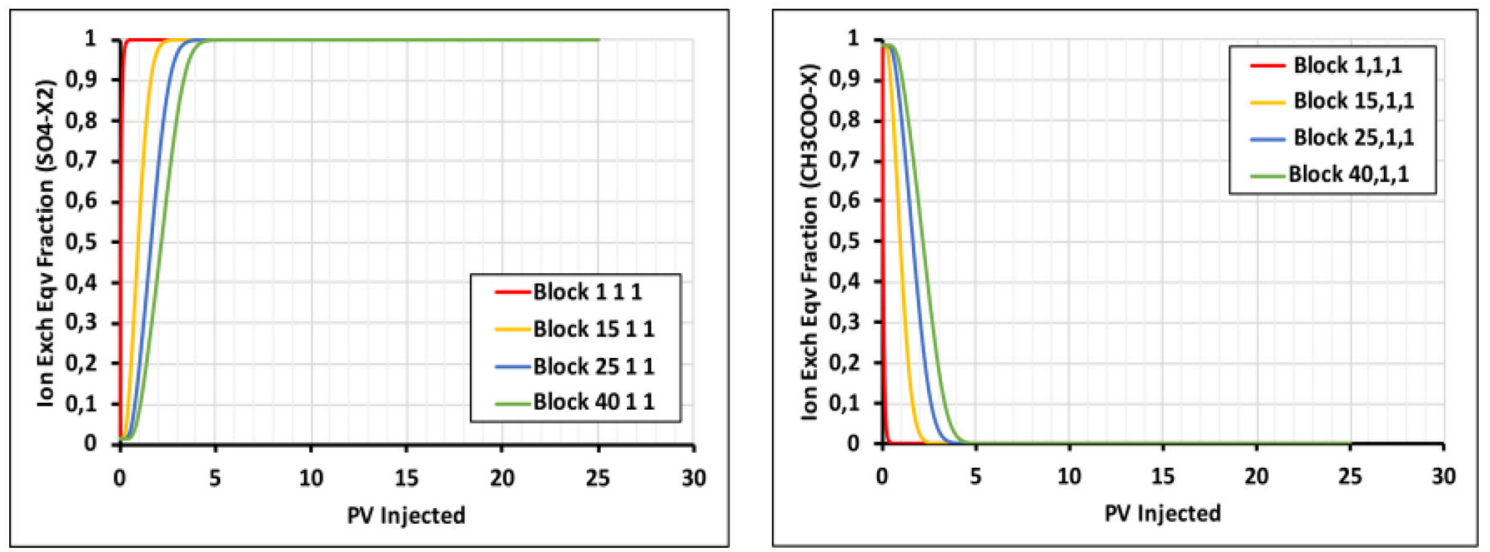

Figure 22. Ion exchange equivalent fraction of sulfate and carboxylic ions for different grid blocks.

Table 13. Oil recovery results using different interpolants

\begin{tabular}{lcc}
\hline Interpolation & \multicolumn{2}{c}{ Oil recovery $(\%$ OOIP) } \\
\cline { 2 - 3 } & Coreflood 1 & Coreflood 2 \\
\hline Base case & 63.10 & 57.69 \\
Anion Exchange & 63.83 & 59.22 \\
$\mathrm{SO}_{4}{ }^{2-}$ Concentration $(\mathrm{ppm})$ & 61.74 & 56.05 \\
\hline
\end{tabular}

- Temperature, water composition and concentration, injection rate and time, rock mineralogy, and oil type all contribute to the improved oil recovery observed during LSWF.

\section{ACKNOWLEDGMENTS}

Open Access funding provided by NTNU Norwegian University of Science and Technology (incl St. Olavs Hospital - Trondheim University Hospital). The authors would like to thank the Department of Geoscience and Petroleum at the Norwegian University of Science and Technology (NTNU) for their support in this work.

\section{OPEN ACCESS}

This article is licensed under a Creative Commons Attribution 4.0 International License, which permits use, sharing, adaptation, distribution and reproduction in any medium or format, as long as you give appropriate credit to the original author(s) and the source, provide a link to the Creative Commons licence, and indicate if changes were made. The images or other third party material in this article are included in the article's Creative Commons licence, unless indicated otherwise in a credit line to the material. If material is not included in the article's Creative Commons licence and your intended use is not permitted by statutory regulation or exceeds the permitted use, you will need to obtain permission directly from the copyright holder. To view a copy of this licence, visit http://creativecom mons.org/licenses/by/4.0/.

\section{REFERENCES}

Adegbite, J. O., Al-Shalabi, E. W., \& Ghosh, B. (2018). Geochemical modeling of engineered water injection effect on oil recovery from carbonate cores. Journal of Petroleum Science and Engineering, 170, 696-711.

Alameri, W., Teklu, T., Kazemi, H., \& Alsumaiti, A. (2015). Lowsalinity Water-alternate-surfactant in Low-permeability Carbonate Reservoirs. In IOR 2015: 18th European symposium on improved oil recovery. https://doi.org/10.3997/22144609.201412158.

Al-Attar, H. H., Mahmoud, M. Y., Zekri, A. Y., Almehaideb, R., \& Ghannam, M. (2013). Low-salinity flooding in a selected carbonate reservoir: Experimental approach. Journal of Exploration and Production Technology, 3, 139-149.

Al-Shalabi, E., Sepehrnoori, K., \& Delshad, M. (2013). Does the double layer expansion mechanism contribute to the LSWI effect on hydrocarbon recovery from carbonate rocks. In SPE Reservoir characterization and simulation conference and exhibition. Abu Dhabi, UAE: Society of Petroleum Engineers.

Al-Shalabi, E. W., Sepehrnoori, K., \& Pope, G. A. (2015). New mobility ratio definition for estimating volumetric sweep efficiency of low salinity water. Fuel, 158, 664-671. 
Altahir, M., Yu, M., \& Hussain, F. (2017). Low salinity water flooding in carbonate rocks: dissolution effect. In International symposium of the society of core analysts. Vienna, Austria.

Appelo, C. A. J., \& Postma, D. (2005). Geochemistry, groundwater and pollution (2nd ed.). Amsterdam: A.A. Balkema Publishers.

Awolayo, A. N., Sarma, H. K., \& Long X. Nghiem. (2017). A comprehensive geochemical-based approach at modeling and interpreting brine dilution in carbonate reservoirs. In $S P E$ reservoir simulation conference (pp. 1-27). https://doi.org/10. 2118/182626-MS.

Bethke, C. M. (1996). Geochemical reaction modeling: Concepts and applications. New York: Oxford University Press.

Brooks, R. H., \& Corey, A. T. (1964). Hydraulic properties of porous media. Hydrology Papers, 3, 1-37.

Chilingar, G. V., \& Yen, T. F. (1983). Some notes on wettability and relative permeabilities of carbonate reservoir rocks, II. Energy Sources, 7(1), 67-75.

Computer Modelling Group Ltd. (2018). GEM: Compositional and unconventional simulator.

Craig, F. F., Jr. (1971). The reservoir engineering aspects of waterflooding: SPE monograph series (Vol. 3). Richardson: American Institute of Mining, Metallurgical and Petroleum engineers Inc.

Dang, C., Nghiem, L., Nguyen, N., Chen, Z., \& Nguyen, Q. (2015). Modeling and optimization of low salinity waterflood. In Proceedings of the SPE reservoir simulation symposium (pp. 1-19). https://doi.org/10.2118/173194-MS.

Dang, C., Nghiem, L., Nguyen, N., Chen, Z., \& Nguyen, Q. (2016). Mechanistic modeling of low salinity water flooding. Journal of Petroleum Science and Engineering, 146, 191-209. https://d oi.org/10.1016/j.petrol.2016.04.024.

Delaney, J. M., \& Lundeen, S. R. (1990). The lawrence livermore national laboratory thermodynamic database. In Lawrence Livermore National Report UCRL-21658.

Derkani, M. H., Fletcher, A. J., Abdallah, W., Sauerer, B., Anderson, J., \& Zhang, Z. J. (2018). LSWF in carbonate reservoirs: Review of interfacial mechanisms. Colloids and Interfaces, 2(20), 1-43.

Hamouda, A. A., \& Gupta, S. (2017). Enhancing oil recovery from chalk reservoirs by a low-salinity water flooding mechanism and fluid/rock interactions. Energies, 10(576), 1-16.

Hiorth, A., Cathles, L. M., Kolnes, J., Vikane, O., Lohne, A., Korsnes, R. I., \& Madland, M. V. (2008). A chemical model for the seawater-CO2-carbonate system: Aqueous and surface chemistry. In International symposium of the society of core analysts. Abu Dhabi: Society of Core Analysts.

Jahanbani G., A., \& Torsæter, O. (2018). Numerical simulation of low salinity water flooding: wettability alteration considerations. In 16th European conference on the mathematics of oil recovery. https://doi.org/10.3997/2214-4609.201802165.

Jahanbani G., A. \& Torsæter, O. (2019). Modeling Wettability Alteration In Low Salinity Water Flooding. In 81st EAGE conference \& exhibition, London. https://doi.org/10.3997/221 4-4609.201900720.

Jerauld, G. R., Lin, C. Y., Webb, K. J., \& Seccombe, J. C. (2008). Modeling low-salinity waterflooding. SPE Reservoir Evaluation \& Engineering, 11(06), 1000-1012. https://doi.org/10.211 8/102239-PA.

Jerauld, G. R., Webb, K. J., Lin, C. Y., \& Seccombe, J. C. (2006). Modeling low-salinity waterflooding. In SPE annual technical conference and exhibition. https://doi.org/10.2118/102239-MS.

Kharaka, Y. K., Gunter, W. D., Aggarwal, P. K., Perkins, E. H., \& DeBraal, J. D. (1989). SOLMINEQ.88: A computer program for geochemical modelling of water-rock reactions. In US Geological Survey Water-Resources Investigations Report 884227.
Lager, A., Webb, K. J., Black, C. J. J., Singleton, M., \& Sorbie, K. S. (2006). Low salinity oil recovery: An experimental investigation. In International symposium of the society of core analysts. Trondheim, Norway.

Lager, A., Webb, K. J., Black, C. J. J., Singleton, M., \& Sorbie, K. S. (2008). Low salinity oil recovery: An experimental investigation. Petrophysics, 49(01), 28-35.

Nasralla, R. A., Mahani, H., van der Linde, H. A., Marcelis, F. H. M., Masalmeh, S. K., Sergienko, E., et al. (2018). LSWF for a carbonate reservoir: Experimental evaluation and numerical interpretation. Journal of Petroleum Science and Engineering, 164, 640-654. https://doi.org/10.1016/j.petrol.2018.01.028.

Nghiem, L., Sammon, P., Grabenstetter, J., \& Ohkuma, H. (2004). Modeling $\mathrm{CO} 2$ storage in aquifers with a fully-coupled geochemical EOS compositional simulator. In SPE/DOE 14th symposium on improved oil recovery (pp. 1-16). https://doi. org/10.2118/89474-MS.

RezaeiDoust, A., Puntervold, T., Strand, S., \& Austad, T. (2009). Smart water as wettability modifier in carbonate and sandstone: A discussion of similarities/differences in the chemical mechanisms. Energy \& Fuels, 23, 4479-4485.

Shaik, I. K., Song, J., Biswal, S. L., Hirasaki, G. J., Bikkina, P. K., \& Aichele, C. P. (2019). Effect of brine type and ionic strength on the wettability alteration of naphthenic-acid-adsorbed calcite surfaces. Journal of Petroleum Science and Engineering. https://doi.org/10.1016/j.petrol.2019.106567.

Shaker Shiran, B., \& Skauge, A. (2013). Enhanced oil recovery (EOR) by combined low salinity water/polymer flooding. Energy \& Fuels, 27, 1223-1235.

Skjaeveland, S. M., Siqveland, L. M., Kjosavik, A., Thomas, W. L. H., \& Virnovsky, G. A. (2000). Capillary pressure correlation for mixed-wet reservoirs. SPE Reservoir Evaluation \& Engineering, 3(1), 60-67.

Sohrabi, M., Mahzari, P., Farzaneh, S. A., Mills, J. R., Tsolis, P., \& Ireland, S. (2017). Novel insights into mechanisms of oil recovery by use of low-salinity-water injection. SPE Journal, 22(02), 407-416.

Srisuriyachai, F., Panthuvichien, S., Phomsuwansiri, T., \& Katekaew, W. (2016). Effects of injection rate of low salinity brine on oil recovery mechanisms and relative permeability curves. In Proceedings of the 78th EAGE conference and exhibition 2016. https://doi.org/10.3997/2214-4609.201600767.

Sun, S. Q., \& Sloan, R. (2003). Quantification of uncertainty in recovery efficiency predictions: Lessons learned from 250 mature carbonate fields. In Proceedings of the SPE annual technical conference and exhibition (pp. 1-15). https://doi.org/ 10.2118/84459-MS.

Teklu, T., Alameri, W., Kazemi, H., Graves, R., \& Alsumaiti, A. (2017). Low salinity water-Surfactant- $\mathrm{CO}_{2}$ EOR. Petroleum, $3,309-320$.

Yousef, A. A., Al-Saleh, S., \& Al-Jawfi, M. (2012). Improved/ enhanced oil recovery from carbonate reservoirs by tuning injection water salinity and ionic content. In SPE improved oil recovery symposium (pp. 1-18). https://doi.org/10.2118/15 4076-MS.

Zhang, P., Tweheyo, M. T., \& Austad, T. (2006). Wettability alteration and improved oil recovery in chalk: The effect of calcium in the presence of sulfate. Energy \& Fuels, 20, 20562062.

Zhang, P., Tweheyo, M. T., \& Austad, T. (2007). Wettability alteration and improved oil recovery by spontaneous imbibition of seawater into chalk: Impact of the potential determining ions $\mathrm{Ca}^{2+}, \mathrm{Mg}^{2+}$, and $\mathrm{SO}_{4}^{2-}$. Colloids and Surfaces $A$, 301, 199-208.

Zhang, Y., \& Morrow, N. R. (2006). Comparison of secondary and tertiary recovery with change in injection brine composition doe crude oil/sandstone combinations. In Proceedings of the 2006 SPE/DOE symposium on improved oil recovery (pp. 114). https://doi.org/10.2118/99757-M. 